Article

\title{
Effect of Surface Treatment of Halloysite Nanotubes (HNTs) on the Kinetics of Epoxy Resin Cure with Amines
}

\author{
Vahideh Akbari ${ }^{1}$, Maryam Jouyandeh ${ }^{2}$, Seyed Mohammad Reza Paran ${ }^{2}$, \\ Mohammad Reza Ganjali ${ }^{2,3}$, Hossein Abdollahi ${ }^{4}$, Henri Vahabi ${ }^{5, * \mathbb{D}}$, Zahed Ahmadi ${ }^{6} \mathbb{D}_{\text {, }}$ \\ Krzysztof Formela ${ }^{7}$ (D), Amin Esmaeili ${ }^{8}$ (D), Ahmad Mohaddespour ${ }^{9}$, Sajjad Habibzadeh ${ }^{10}$ and \\ Mohammad Reza Saeb ${ }^{1, *(1)}$
}

1 Department of Resin and Additives, Institute for Color Science and Technology, Tehran P.O. Box: 16765-654, Iran; vahidehakbari1991@gmail.com

2 Center of Excellence in Electrochemistry, School of Chemistry, College of Science, University of Tehran, Tehran 11155-4563, Iran; maryam.jouyandeh@gmail.com (M.J.); smrparan@gmail.com (S.M.R.P.); ganjali@ut.ac.ir (M.R.G.)

3 Biosensor Research Center, Endocrinology and Metabolism Molecular-Cellular Sciences Institute, Tehran University of Medical Sciences, Tehran 11155-4563, Iran

4 Department of Polymer Engineering, Faculty of Engineering, Urmia University, Urmia 5756151818-165, Iran; h.abdollahi@urmia.ac.ir

5 Université de Lorraine, CentraleSupélec, LMOPS, F-57000 Metz, France

6 Department of Chemistry, Amirkabir University of Technology, Tehran 1591634311, Iran; zahmadi@aut.ac.ir

7 Department of Polymer Technology, Faculty of Chemistry, Gdańsk University of Technology, Gabriela Narutowicza 11/12, 80-233 Gdańsk, Poland; krzysztof.formela@pg.edu.pl

8 Department of Chemical Engineering, School of Engineering Technology and Industrial Trades, College of the North Atlantic-Qatar, 24449 Arab League St, Doha 24449, Qatar; amin.esmaeili@cna-qatar.edu.qa

9 Department of Chemical Engineering, College of Engineering and Technology, American University of Middle East, Egaila 15453, Kuwait; ahmad.mohaddespour@mail.mcgill.ca

10 Department of Chemical Engineering, Amirkabir University of Technology (Tehran Polytechnic), Tehran 1591634311, Iran; sajjad.habibzadeh@aut.ac.ir

* Correspondence: henri.vahabi@univ-lorraine.fr (H.V.); saeb@icrc.ac.ir (M.R.S.); Tel.: +33(0)387939186 (H.V.); +98(21)22956209 (M.R.S.); Fax: +33(0)387939101 (H.V.); +98(21)22947537 (M.R.S.)

Received: 21 March 2020; Accepted: 13 April 2020; Published: 17 April 2020

check for updates

\begin{abstract}
The epoxy/clay nanocomposites have been extensively considered over years because of their low cost and excellent performance. Halloysite nanotubes (HNTs) are unique 1D natural nanofillers with a hollow tubular shape and high aspect ratio. To tackle poor dispersion of the pristine halloysite (P-HNT) in the epoxy matrix, alkali surface-treated HNT (A-HNT) and epoxy silane functionalized HNT (F-HNT) were developed and cured with epoxy resin. Nonisothermal differential scanning calorimetry (DSC) analyses were performed on epoxy nanocomposites containing $0.1 \mathrm{wt} . \%$ of P-HNT, A-HNT, and F-HNT. Quantitative analysis of the cure kinetics of epoxy/amine system made by isoconversional Kissinger-Akahira-Sunose (KAS) and Friedman methods made possible calculation of the activation energy $\left(E_{\alpha}\right)$ as a function of conversion $(\alpha)$. The activation energy gradually increased by increasing $\alpha$ due to the diffusion-control mechanism. However, the average value of $E_{\alpha}$ for nanocomposites was lower comparably, suggesting autocatalytic curing mechanism. Detailed assessment revealed that autocatalytic reaction degree, $m$ increased at low heating rate from 0.107 for neat epoxy/amine system to 0.908 and 0.24 for epoxy/P-HNT and epoxy/A-HNT nanocomposites, respectively, whereas epoxy/F-HNT system had $m$ value of 0.072 as a signature of dominance of non-catalytic reactions. At high heating rates, a similar behavior but not that significant was observed due to the accelerated gelation in the system. In fact, by the introduction of nanotubes
\end{abstract}


the mobility of curing moieties decreased resulting in some deviation of experimental cure rate values from the predicted values obtained using KAS and Friedman methods.

Keywords: cure kinetics; halloysite nanotubes; epoxy; isoconversional method

\section{Introduction}

The curing reaction of epoxy resin, so-called crosslinking, includes formation of short chains followed by branching until formation of a cross-linked network [1-3]. Curing process of epoxy progresses further by the occurrence of gelation and vitrification transitions that affect the ultimate properties of the cured system [4-6]. The cure reaction of epoxy and consequently its properties are additionally dependent on the fillers involved in the formulation and the interactions between filler and the matrix [7-9]. The interfacial interaction between fillers and polymer matrix can be improved by adjusting the surface chemistry of the reinforcing agents. Moreover, the morphology of nanoparticles and their content can strongly affect cross-linking reaction of epoxy. The cure study of epoxy containing 0D spherical cobalt doped $\mathrm{Fe}_{3} \mathrm{O}_{4}$ nanoparticles revealed that the amount of heat of cure of nanocomposite was significantly higher than that for the neat epoxy system due to the catalytic effect of nanoparticles [10]. In another study, surface modification of cobalt doped $\mathrm{Fe}_{3} \mathrm{O}_{4}$ nanoparticles with ethylenediaminetetraacetic acid enhanced the curability of epoxy nanocomposite because of the reaction between the carboxylic acid anchored to the surface of particles and the epoxide rings [11]. Nonisothermal differential scanning calorimetry (DSC) results indicated that epoxy nanocomposite containing Ni-Al- $\mathrm{NO}_{3} 2 \mathrm{D}$ layered double hydroxide platelet-like nanoparticles increased the cross-link density of network compared to the unfilled epoxy due to the reaction of nitrate anion with epoxide ring [12]. In a recent study, it was found that introduction of $0.1 \mathrm{wt} . \%$ microporous 3D metal-organic framework into the epoxy significantly improved the heat release by $63 \%$ [13].

Among 1D nano-scale fillers, halloysite nanotubes (HNTs) are of interest of researchers because of being inexpensive and having a highly reactive surface [14-16]. In recent years, many studies published on the effect of HNT as filler on the thermal stability, mechanical, anticorrosion, and flame retardant properties of polymers [17-22]. Biocompatibility and availability are two important factors placing reason behind selection of HNTs $[23,24]$. However, there is still a shortage of resources in the study of network formation and the effects of thermal phenomena on the properties of HNT/epoxy nanocomposites. Vahedi et al. [25] studied isothermal cure behavior of epoxy/HNT nanocomposites with two different curing agents of diaminodiphenylmethane (MDA) and diethylenetriamine (DETA). They indicated that the curing behavior of the cured epoxy with DETA was not severely affected by the addition of HNTs. However, HNTs showed catalytic effect on the curing behavior of MDA cured epoxy due to the presence of hydroxyl groups on the surface of HNTs. The effect of $0.5,1.0$ and $2.0 \mathrm{wt} . \%$ of HNTs on the curing behavior of epoxy/anhydride systems was also discussed by Jouyandeh et al. [26]. The results indicated that the crosslinking reaction was promoted at 0.5 and $1.0 \mathrm{wt} . \%$ of HNTs, while the curing reaction was hindered at $2.0 \mathrm{wt} . \%$ of HNTs because of deactivation of anhydride curing agent fueled by diffusion into the lumen of HNTs.

In a recent work, pristine HNT (P-HNT) was modified by alkali activation process (A-HNT) and epoxy silane functionalization (F-HNT) as well. The potentials of P-HNT, A-HNT and F-HNT to cure with epoxy and amine were studied qualitatively by nonisothermal DSC [27]. In order to gain more information about cure reaction of epoxy containing P-HNT, A-HNT and F-HNT, Cure Index (CI) was used [28]. However, to unravel complexities in the system, e.g., the effect of each type of nanotubes on the autocatalytic and non-catalytic crosslinking reactions, we needed isoconversional kinetic analyses to provide more detailed quantitative information on crosslinking reactions by patterning the evolution of activation energy of systems as a function of conversion and the orders of the aforementioned crosslinking reactions. 
In this work, cure kinetics of epoxy/HNT nanocomposites was comprehensively studied through quantitative analysis of network formation in the epoxy/amine systems filled with P-HNT, A-HNT and F-HNT. Following the previous work, we more accurately investigate the curing reaction, accomplished by the calculations based on integral Kissinger-Akahira-Sunose (KAS) and differential Friedman isoconversional methods.

\section{Materials and Methods}

\subsection{Materials}

Bisphenol A diglycidyl ether (EPON ${ }^{\mathrm{TM}}$ Resin 828$)$ epoxy resin with epoxide equivalent weight of 450-550 g/eq. was provided by Hexion (Shanghai, China). The curing agent of Epikure ${ }^{\mathrm{TM}}$ F205 with hydrogen equivalent weight (HEW) value of $105 \mathrm{~g} / \mathrm{eq}$. was provided by Hexion (Shanghai, China). HNTs with lumen diameter of 15-70 nm, outer diameter of 50-200 nm and the length of 100-3000 nm was purchased from Imerys Tableware Asia Limited (Auckland, New Zealand).

\subsection{Preparation of Epoxy Nanocomposites}

Pristine halloysite nanotubes (P-HNTs), alkali-activated HNTs (A-HNTs), and epoxy silane (2-(3,4-epoxycyclohexyl) ethyltriethoxy silane)-functionalized A-HNTs (F-HNTs) were prepared according to the previous work [19]. For preparation of epoxy/HNTs nanocomposites, $0.2 \mathrm{wt} . \%$ P-HNTs, A-HNTs and F-HNTs were separately added to the epoxy resin under sonication for $30 \mathrm{~min}$. Then, the amine curing agent was added to the resulting nanocomposites at 2:1 resin:curing agent ratio at room temperature and stirred for $3 \mathrm{~min}$. The prepared samples were stored at $-4{ }^{\circ} \mathrm{C}$ prior to calorimetric measurements.

\subsection{DSC Measurement}

Cure reactions of epoxy in the presence of P-HNTs, A-HNTs and F-HNTs were studied by nonisothermal DSC on a model DSC1 Mettler device (Greifensee, Switzerland). Samples of about $15 \mathrm{mg}$ were analyzed under nitrogen atmosphere at heating rates of $5,10,15$, and $20^{\circ} \mathrm{C} / \mathrm{min}$. The nonisothermal DSC test was performed in the temperature range between the room temperature and $300^{\circ} \mathrm{C}$ to cover the whole curing process.

\section{Results and Discussion}

Based on a comprehensive protocol recommended for the analysis of cure process in thermoset composites [29], the results of nonisothermal DSC at four heating rates of 5, 10, 15 and $20^{\circ} \mathrm{C} / \mathrm{min}$ were analyzed for neat epoxy and its nanocomposites. Figure 1 shows the DSC data of the neat epoxy and its nanocomposites including $0.2 \mathrm{wt} . \%$ of P-HNT, A-HNT and F-HNT. DSC thermograms for each sample were shifted towards higher temperatures by increasing the heating rate, suggesting enhanced kinetic energy of the system at higher heating rates [30-32]. Observation of a single exothermic peak in the thermogram of the neat epoxy confirmed the single-step curing kinetic assumption $[33,34]$. The existence of a small shoulder in the case of epoxy/P-HNT nanocomposite was the characteristics of the complexity of curing reaction in this system. In fact, the presence of hydroxyl groups on the surface of P-HNT with less reactivity compared to the amine groups of curing agent resulted in epoxide ring opening at the later stages of curing reaction. As a result, a small shoulder was observed in the DSC thermograms at high temperatures. In the case of A-HNT incorporated epoxy system, this shoulder was disappeared due to the alkali activation of HNT where some loci of the inner surface of HNT were etched and the $\mathrm{OH}$ groups decreased in number compared to the P-HNT [27]. However, OH groups were formed during the reaction of epoxy on the surface of F-HNT with amine groups of curing agent by surface modification of HNT with epoxy silane coupling agent, and again a shoulder appeared at higher temperatures. Therefore, P-HNT and A-HNT assisted curing agent, while F-HNT somewhat compensated the stoichiometry for epoxy resin. 
(a)

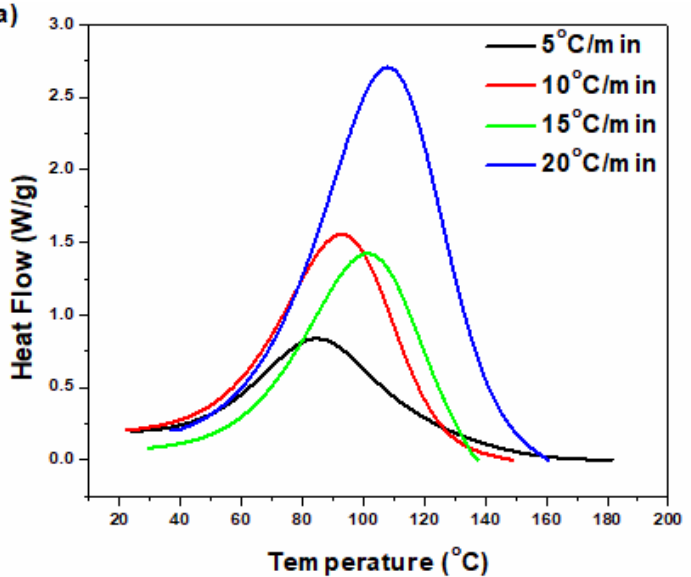

(c)

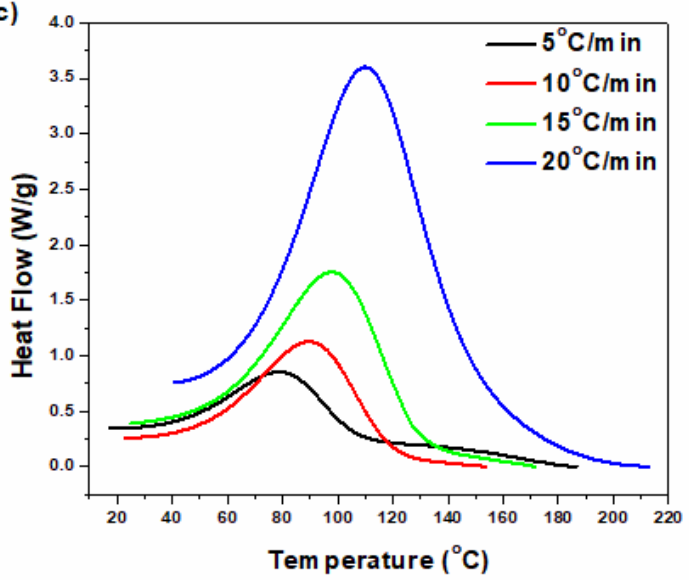

(b)

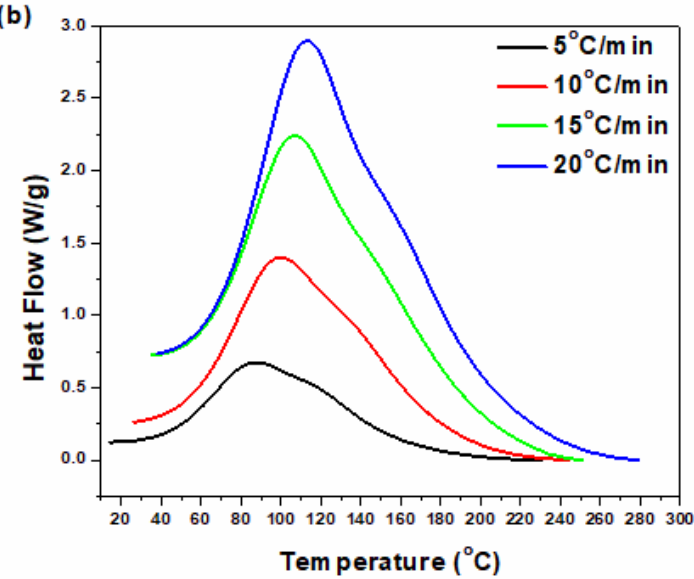

(d)

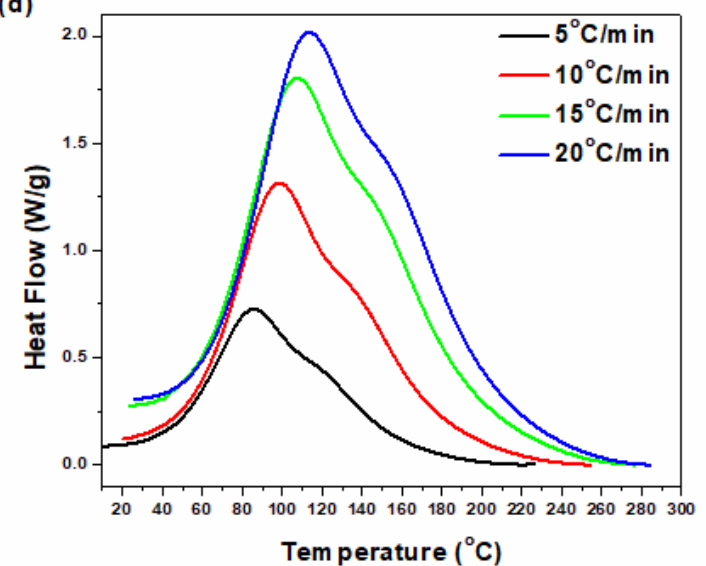

Figure 1. DSC thermographs of the (a) neat epoxy, (b) epoxy/P-HNT, (c) epoxy/A-HNT and (d) epoxy/F-HNT at four different heating rates of 5, 10, 15 and $20{ }^{\circ} \mathrm{C} \min ^{-1}$ [27].

\subsection{Cure Behavior}

Studying the cure behavior of epoxy nanocomposites helps one to collect information on the role of nanoparticles on accelerating or decelerating the cure reaction rate. Curing conversion $(\alpha)$ is one of the first evaluation terms for studying the cure behavior of thermosetting systems, derived from the Equation (1) [35]:

$$
\alpha=\frac{\Delta H_{T}}{\Delta H_{\infty}}
$$

where $\Delta H_{T}$ is the heat of cure at a certain temperature and $\Delta H_{\infty}$ is the total heat of cure reaction. The data calculated from Equation (1) for neat epoxy and its nanocomposites as a function of curing time are depicted in Figure 2. The sigmoidal shape of conversion curves observed for the neat epoxy, epoxy/P-HNT, epoxy/A-HNT and epoxy/F-HNT was served as a signature of the autocatalytic nature of curing process [36]. In the beginning of the curing reaction, $\alpha$ was increased slowly until reaching gel point where a dramatic increase in the extent of reaction was observed, and ultimately again the $\alpha$ increased slowly until the complete cure [37]. 
(a)

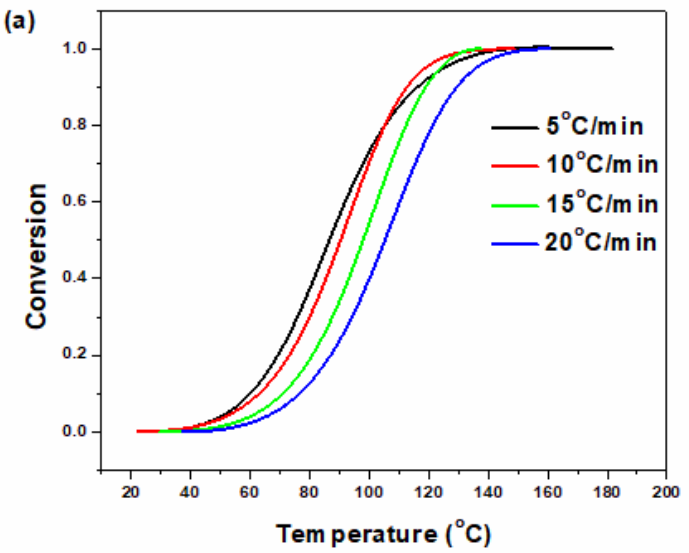

(c)

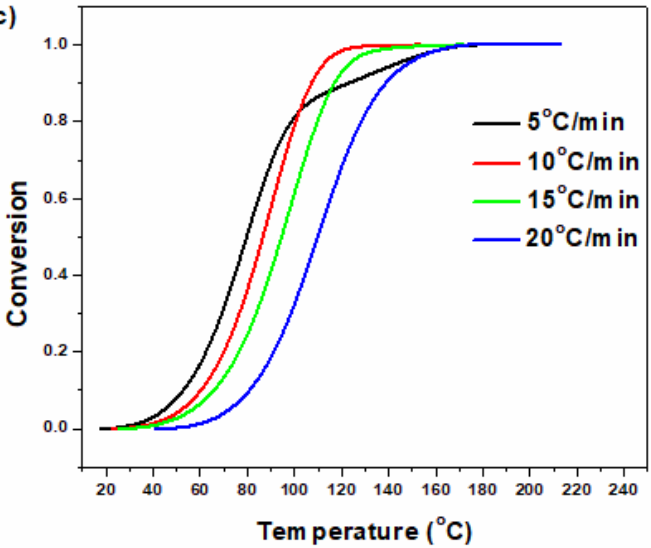

(b)

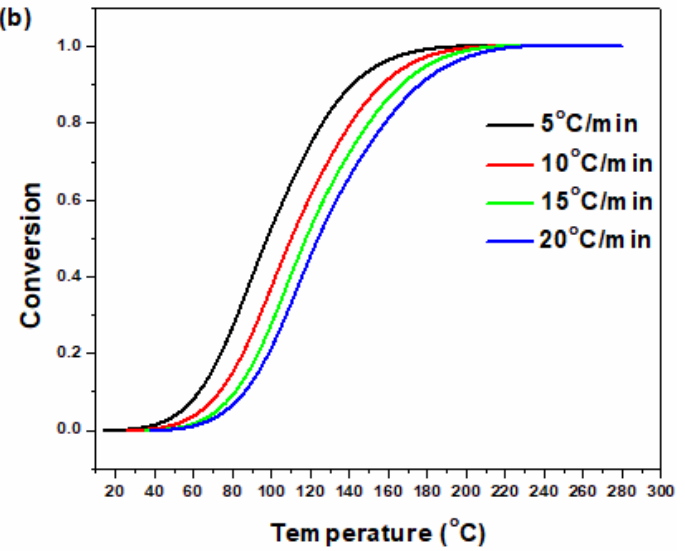

(d)

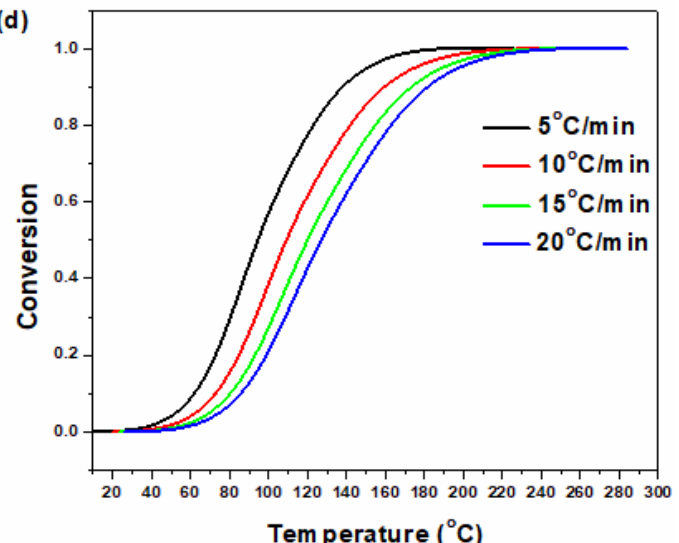

Figure 2. Fractional extent of conversion for neat epoxy and its nanocomposites at heating rates of (a) 5 , (b) 10 , (c) 15 and (d) $20^{\circ} \mathrm{C} \mathrm{min}^{-1}$.

\subsection{Cure Kinetics}

The rate of epoxy cure reaction is measured by the following equation:

$$
\frac{d \alpha}{d t}=k(T) f(\alpha)
$$

In Equation (2), $f(\alpha)$ is the reaction model and $k(T)$ is the reaction rate constant, which is defined based on Arrhenius equation as [38]:

$$
k(T)=A \exp \left(-\frac{E_{\alpha}}{R T}\right)
$$

where $A$ is the pre-exponential (also known as frequency factor), $R$ is the universal gas constant and the $E_{\alpha}$ is the activation energy of the curing reaction.

By substituting Equation (3) into the Equation (2), the rate of cure can be obtained as:

$$
\frac{d \alpha}{d t}=A \exp \left(-\frac{E_{\alpha}}{R T}\right) f(\alpha)
$$

For nonisothermal curing reaction, Equation (4) can be reformed as follows by introducing the heating rate $(\beta=d T / d t)$ :

$$
\frac{d \alpha}{d T}=\left(\frac{A}{\beta}\right) \exp \left(-\frac{E_{\alpha}}{R T}\right) f(\alpha),
$$

Model-free (isoconversional) method was used for evaluating kinetic parameters of epoxy system in the presence of P-HNT, A-HNT and F-HNT. According to the isoconversional models, the reaction 
rate at a given conversion $(\alpha)$ is merely a function of temperature [39]. The model-free isoconversional method is divided into two types of differential and integral methods. Among the differential isoconversional methods, the Friedman method is the most frequently used one, defined as [40]:

$$
\ln \left(\frac{d \alpha}{d t}\right)_{\alpha}=\ln \left[f(\alpha) A_{\alpha}\right]-\frac{E_{\alpha}}{R T_{\alpha}}
$$

The activation energy is calculated from the slope of the plot of $\ln (d \alpha / d t)_{\alpha}$ against $1 / T_{\alpha}$ at a certain $\alpha$. The $K A S$ is a well-known accurate integral isoconversional method, which calculates the activation energy through the slope of the curve of $\ln \left(\beta_{i} / T_{\alpha, i}^{2}\right)$ against $1 / T$ by the following equation [41]:

$$
\ln \left(\frac{d \alpha}{d t}\right)_{\alpha}=\ln \left[f(\alpha) A_{\alpha}\right]-\frac{E_{\alpha}}{R T_{\alpha}}
$$

Figures 3 and 4 show the typical isoconversional plots based on Friedman and KAS methods, respectively. The fitted lines in the Friedman and KAS methods are parallel with each other at $0.2<\alpha<0.9$, suggesting a single cure kinetics mechanism exists in this $\alpha$ range. This also indicates the inaccuracy of models at the initial and final stages of curing reaction when the cure processes is under the control of chemical reaction and diffusion, respectively [42].

(a)

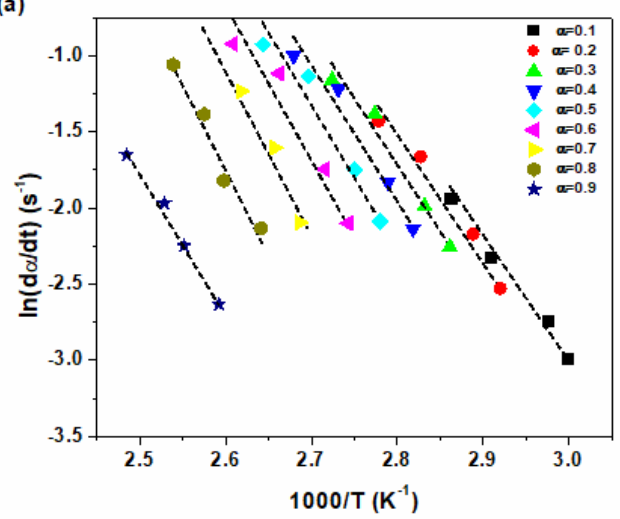

(c)

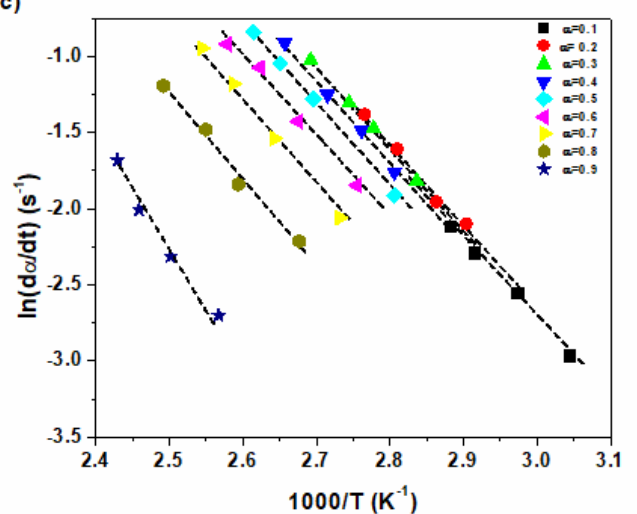

(b)

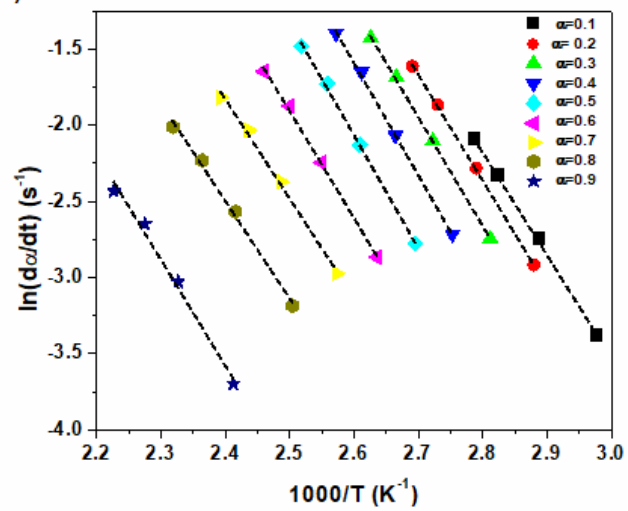

(d)

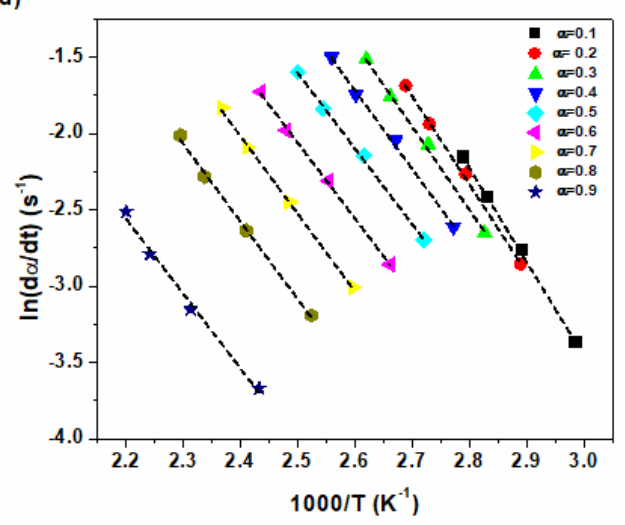

Figure 3. Plots of $\ln (d \alpha / d t)$ vs. 1/T for (a) epoxy resin, (b) epoxy/P-HNT and (c) epoxy/A-HNT and (d) epoxy/F-HNT nanocomposites based on Friedman model. 
(a)

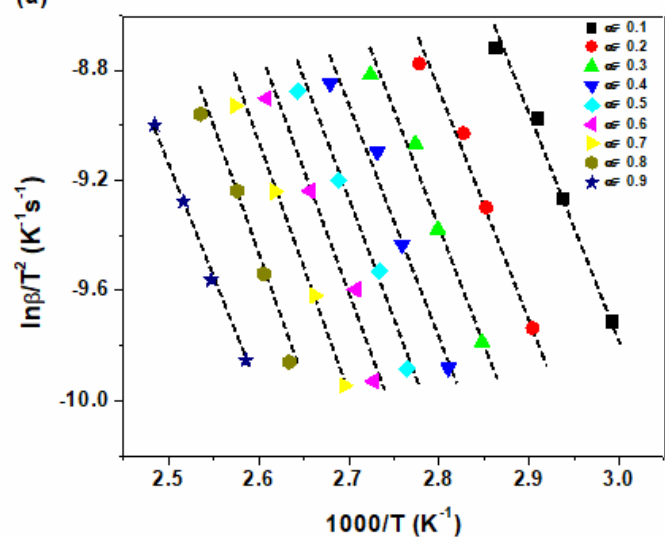

(c)

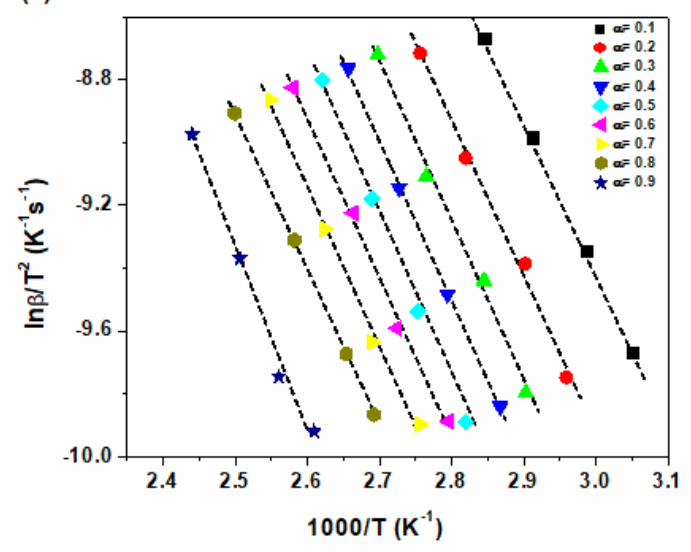

(b)

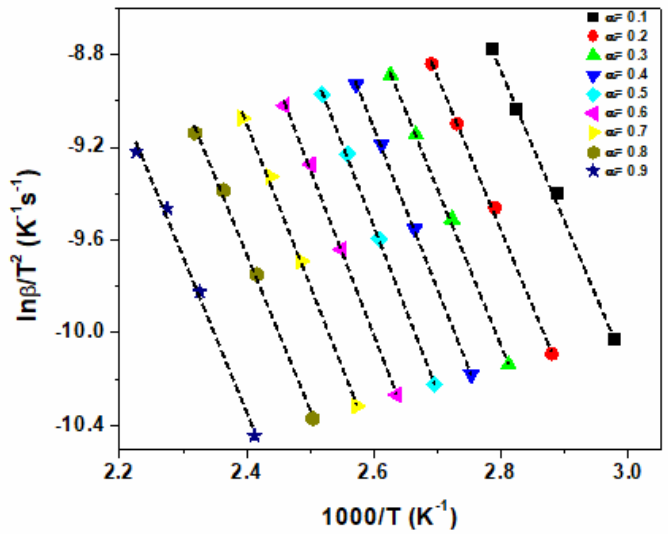

(d)

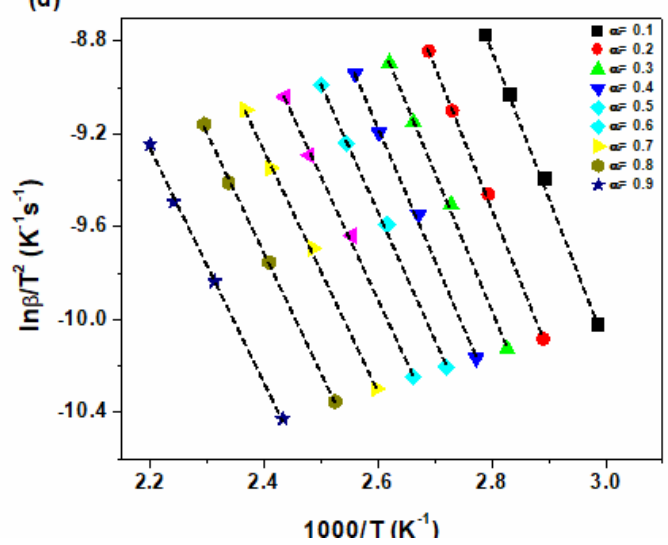

Figure 4. Plots of $\ln \left(\beta / T^{2}\right)$ vs. $1 / T$ for (a) epoxy resin, (b) epoxy/P-HNT and (c) epoxy/A-HNT and (d) epoxy/F-HNT nanocomposites based on KAS model.

Figure 5 shows the changes in activation energy of cure reaction versus the extent of reaction for the epoxy resin and its nanocomposites containing $0.2 \mathrm{wt}$ \% P-HNT, A-HNT and F-HNT based on the Friedman and KAS models. Besides, for explicit specification, a schematic illustration of the epoxy resin and its nanocomposites are depicted in Figure 6.

(a)

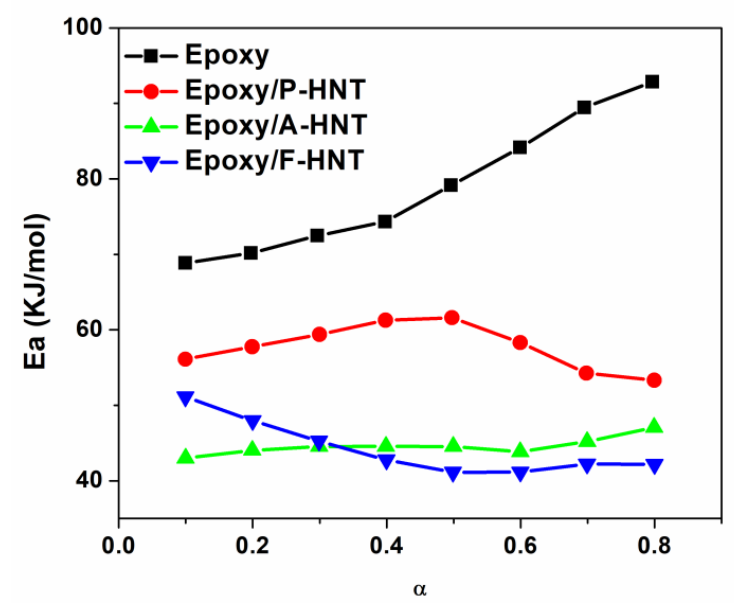

(b)

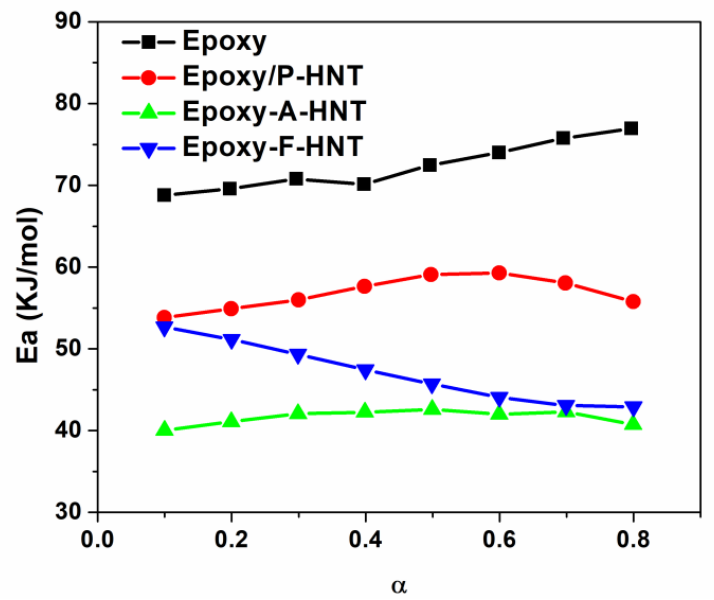

Figure 5. Variation of $E_{\alpha}$ versus conversion for epoxy resin and prepared nanocomposites derived from (a) Friedman model and (b) KAS model. 
a)

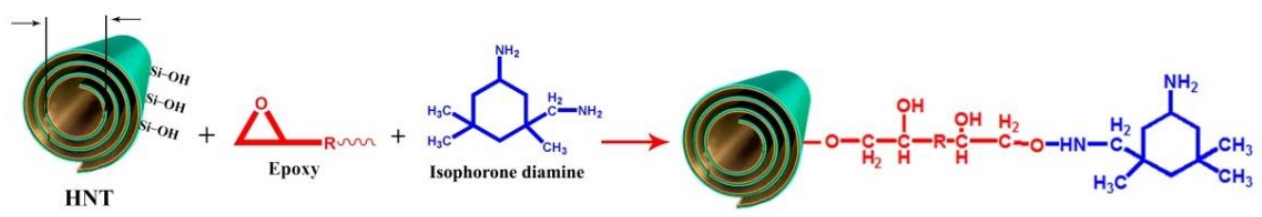

b)

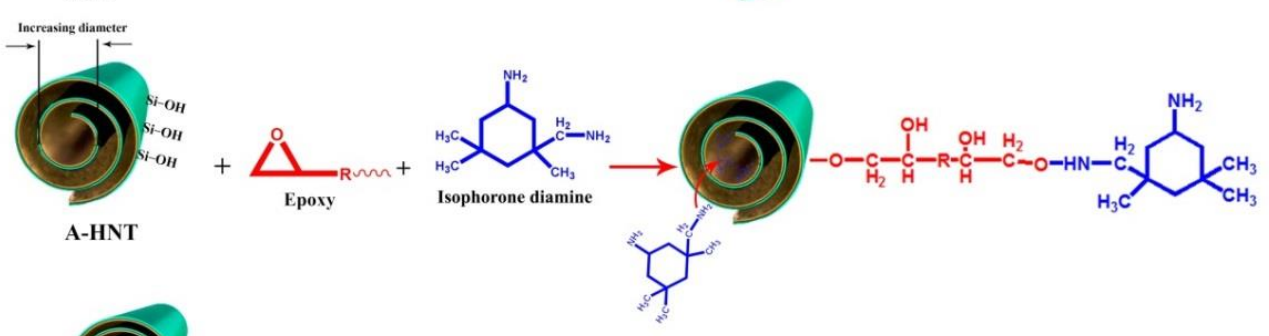

c)
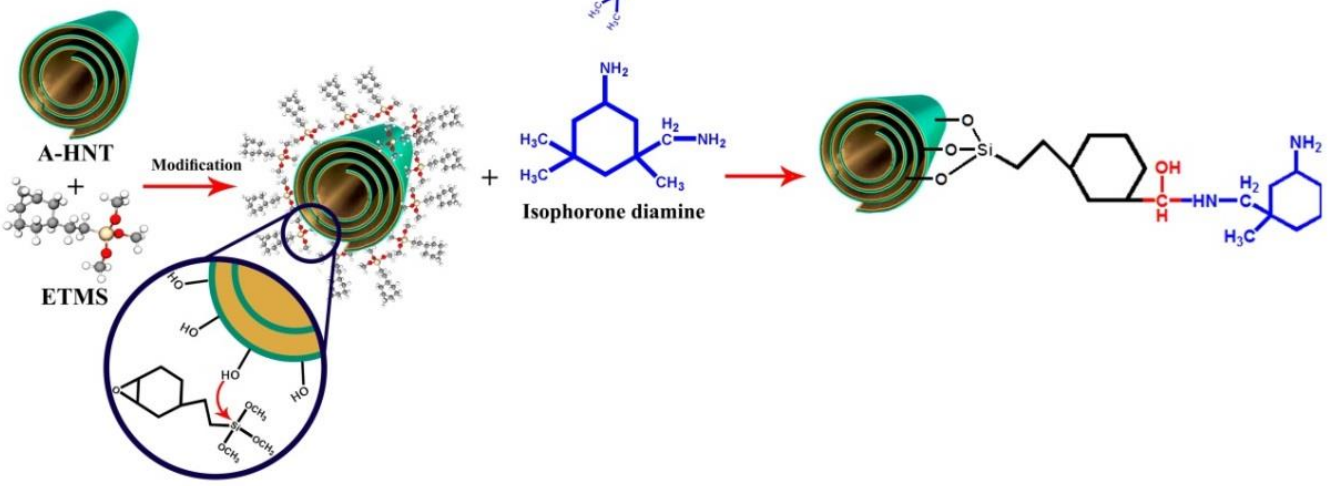

Figure 6. Possible reaction of (a) P-HNT and epoxy, (b) A-HNT with epoxy and amine curing agent and (c) F-HNT with amine group of curing agent.

As expected, the data from the Friedman and KAS models are relatively alike. It should be noted that the predicted activation energies in the range of $\alpha>0.8$ and $\alpha<0.2$ are generally unreliable. According to Figure 5, the activation energy values for the neat epoxy are higher than the nanocomposites. The activation energy for neat epoxy increases gradually by increasing the curing conversion due to the decrement of the free volume of the system as the crosslinking reactions occurs. As a result, the activation energy is increased in the late curing stage due to the gelation, glass transition and the rise in the reaction viscosity when the reaction is controlled by the diffusion [43].

As can be observed from Figure 5, the activation energy decreased for samples including nanofillers. Addition of P-HNT into the epoxy matrix results in growth of heat of cure and decline in activation energy due to the increase in the number of effective interactions caused by the presence of $\mathrm{OH}$ groups on the surface of HNT that facilitate the curing reaction [44]. Moreover, the activation energy is slowly increasing at lower conversion rates, due to the reduction in free volume fueled by the gelation phenomenon. By contrast, at higher conversions the hydroxyl groups of HNT can participate in the epoxide ring opening at late stage of curing [45]. Amine groups of curing agent are more reactive than the hydroxyl groups on the surface of P-HNT; therefore, they participate in epoxy ring opening in the early stage of cure through the interaction of primary and secondary amines of curing agent with the epoxy groups. In the presence of P-HNT with hydroxyl-rich surface, catalytic curing reaction takes place via etherification reaction when the amine groups of curing agent are consumed or somehow remained unreacted in the gelled network in the later stage of cure [46] (Figure 6a).

According to Figure 5, the activation energy values for samples containing active and modified HNTs (A-HNT and F-HNT) are less than the other two samples. Reduction in activation energy for the A-HNT/epoxy cannot principally be a signature of facilitated cure, instead springs from the lack of evolution in the curing reaction. Alkali activation of HNT results in removal of the inner surface of nanotube as $\mathrm{Al}(\mathrm{OH})_{3}$ sheets, which cause fall in the inner hydroxyl groups and rise in the inner diameter [27]. Therefore, in the epoxy/A-HNT system the hydroxyl groups decreased compared to $\mathrm{P}-\mathrm{HNT}$ and consequently the possibility of reaction between $\mathrm{OH}$ groups and epoxy rings should 
be decreased. On the other hand, the amino groups that are responsible for the curing reaction are probably trapped inside the nanoparticles and become inaccessible, resulting in an incomplete curing reaction (Figure $6 b$ ).

Conversely, by modification of surface of HNT by silane coupling agent the activation energy decreases beside the increases in heat of cure indicates facilitation of crosslinking reaction. Epoxy silane coupling agent on the surface of F-HNTs can react with amine groups of curing agent which prevents re-aggregation of nanotubes in epoxy/curing agent system and results in more stable dispersion. Moreover, hydroxyl groups form during the reaction of epoxy groups on the surface of F-HNT with amine groups of curing agent as shown in Figure $6 c$, so the etherification reaction could be more highlighted and the cure process push towards to the reaction between hydroxyl groups and epoxy ring.

\subsubsection{Determining Reaction Model}

Determination of the reaction model is an important step for deeper understanding that whether addition of P-HNT, AHNT and F-HNT can change the curing reaction mechanism. So, the goal is to find appropriate $f(\alpha)$ which correlate as close as possible with the experimental data. For epoxy system the nth order or two component autocatalytic reaction models could be considered. The $n$th order reaction model is defined as follows:

$$
f(\alpha)=(1-\alpha)^{n},
$$

Moreover, Sestak and Berggren [47] proposed an empirical kinetic model as follows:

$$
f(\alpha)=\alpha^{m}(1-\alpha)^{n},
$$

where $m$ and $n$ are the reaction orders. Friedman and Malek methods are two common approaches for determination of reaction model.

\section{Friedman Method}

Based on the Friedman method, the curing reaction model for epoxy system in the presence of P-HNT, A-HNT and F-HNT can be determined using Equation (10).

$$
\ln [A f(\alpha)]=\ln \left(\frac{d \alpha}{d t}\right)+\frac{E}{R T}=\ln A+n \ln (1-\alpha)
$$

The plot of $\ln [A f(\alpha)]$ as a function of $\ln (1-\alpha)$ for neat epoxy and its nanocomposites is shown in Figure 7 which shape denotes the deviation from nth order reaction. A straight line was obtained for noncatalytic nth order cure mechanism as a result of plotting $\ln [A f(\alpha)]$ vs. $\ln (1-\alpha)$. As it is clear in Figure 7, the Friedman curves for both neat epoxy and its nanocomposites show a maximum with in the conversion range between $0.2-0.4$ which is indicative of autocatalytic reaction mechanism.

\section{Malek Method}

The kinetic model based on the Malek method can be determined using the following functions:

$$
\begin{gathered}
y(\alpha)=\left(\frac{d \alpha}{d t}\right)_{\alpha} \exp \left(\frac{E_{0}}{R T_{\alpha}}\right)=A f(\alpha), \\
z(\alpha)=\left(\frac{d \alpha}{d t}\right)_{\alpha} T_{\alpha}^{2}\left[\frac{\pi(x)}{\beta T_{\alpha}}\right]
\end{gathered}
$$

The term in the bracket of Equation (12) can be omitted due to its low impact on the shape of the $z(\alpha)$ function. The constant $E_{0}$ value in Equation (11) can be determined by FWO method (where the activation energy does not change with variation of $\alpha$ as follows: 


$$
\ln \left(\beta_{i}\right)=\text { Const }-1.052\left(\frac{E_{\alpha}}{R T_{\alpha}}\right),
$$

The activation energy is determined from the slope of $\ln \left(\beta_{i}\right)$ vs. 1/T as shown in Figure 8.

(a)

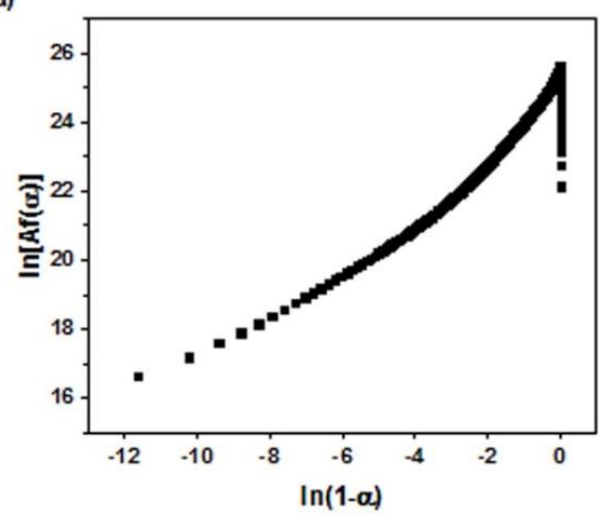

(c)

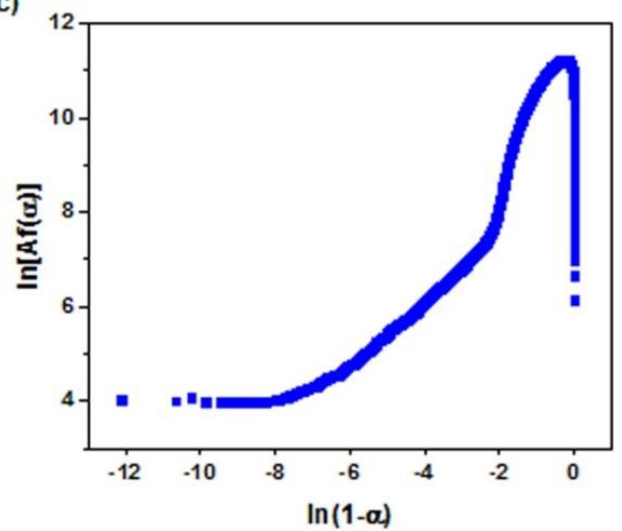

(b)

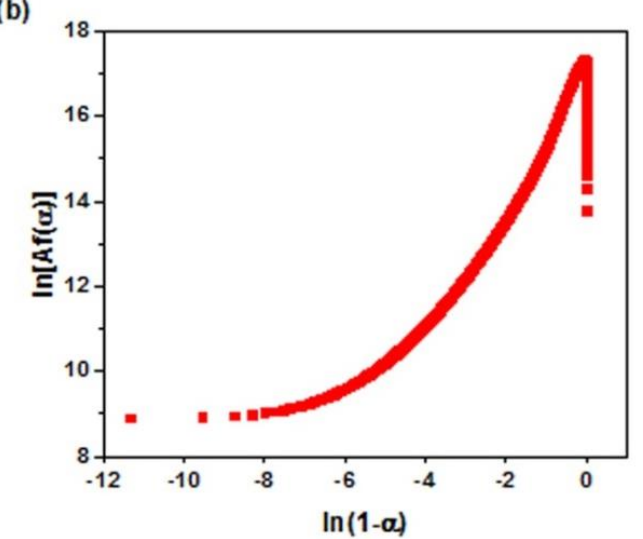

(d)

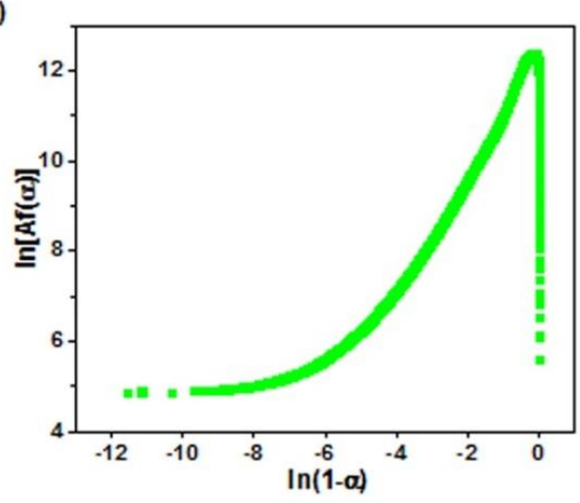

Figure 7. Plots of $\ln [A f(\alpha)]$ vs. $\ln (1-\alpha)$ for (a) neat epoxy, (b) epoxy/P-HNT, (c) epoxy/A-HNT and (d) epoxy/F-HNT.

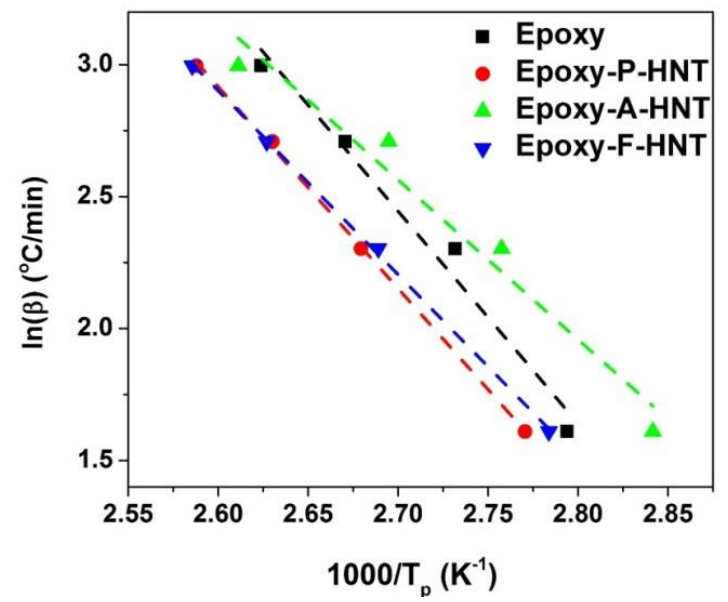

Figure 8. Plots of $\ln \left(\beta_{i}\right)$ vs. 1/T for neat epoxy, epoxy/P-HNT, epoxy/A-HNT and epoxy/F-HNT nanocomposites based on $F W O$ model.

The experimental values of $y(\alpha)$ and $z(\alpha)$ for neat epoxy and its nanocomposites containing 0.2 mass $\%$ of P-HNT, A-HNT and F-HNT are shown in Figure 9 and compared with theoretical master plots. The curing reaction model for neat epoxy and its nanocomposites can be determined as the best match between the experimental (Figure 9) and theoretical master plots [48]. 
(a)

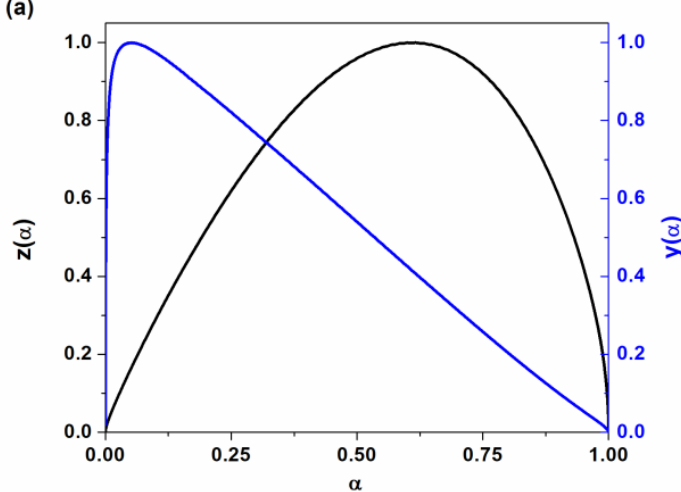

(c)

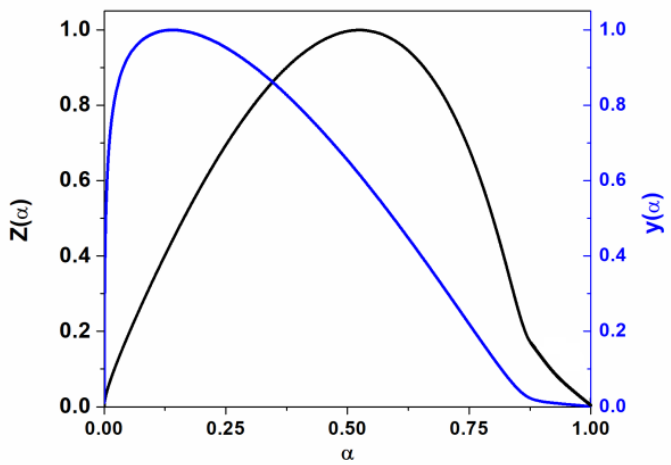

(b)

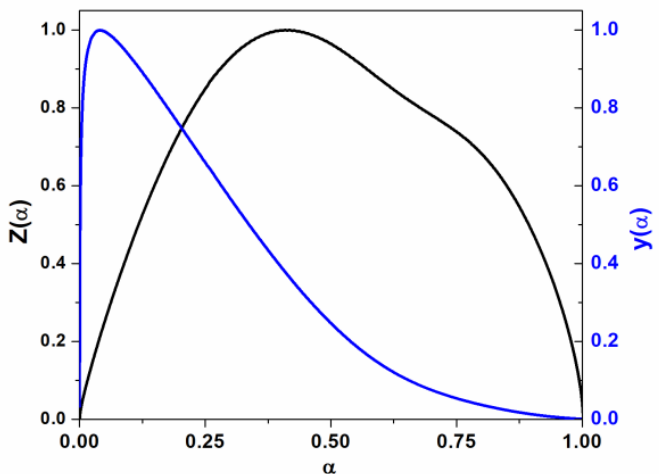

(d)

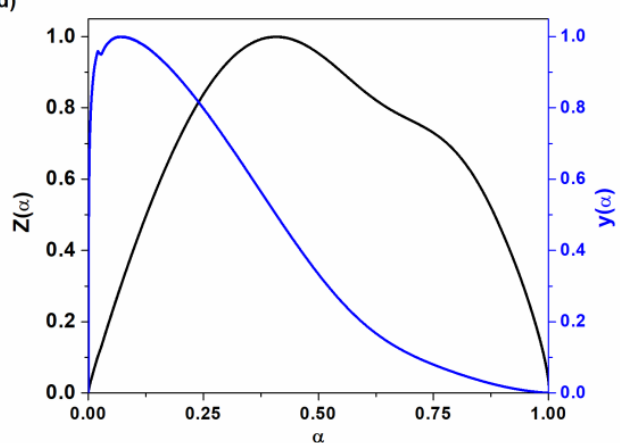

Figure 9. Variation of $y(\alpha)$ and $Z(\alpha)$ versus conversion for (a) neat epoxy, (b) epoxy/P-HNT, (c) epoxy/A-HNT and (d) epoxy/F-HNT nanocomposites based on Malek model.

As can be observed from Figure 9, $y(\alpha)$ and $z(\alpha)$ shows a maximum point at $\alpha_{\mathrm{m}}$, and $\alpha_{\mathrm{p}}{ }^{\infty}$, respectively. The values of $\alpha_{m}, \alpha_{p}{ }^{\infty}$ and $\alpha_{p}$ ( $\alpha_{p}$ can be obtained from DSC peak) for neat epoxy and its nanocomposites at different heating rates are reported in Table 1 . The shapes of $\mathrm{y}\left(\alpha_{\mathrm{p}}\right)$ and $\mathrm{z}\left(\alpha_{\mathrm{p}}\right)$ in Figure 9 and the values of $\alpha_{m}$ which are lower than $\alpha_{p}$ and $\alpha_{p}{ }^{\infty}<0.632$ indicated two-parameter autocatalytic kinetic model.

Table 1. The values of $\alpha_{\mathrm{p}}, \alpha_{\mathrm{m}}$ and $\alpha_{\mathrm{p}}{ }^{\infty}$ obtained from DSC analysis based on Malek model at various heating rates.

\begin{tabular}{ccccc}
\hline Designation & Heating Rate $\left({ }^{\circ} \mathbf{C} / \mathbf{m i n}\right)$ & $\alpha_{\mathrm{p}}{ }^{\infty}$ & $\alpha_{\mathrm{m}}$ & $\alpha_{\mathrm{p}}$ \\
\hline \multirow{3}{*}{ Epoxy } & 5 & 0.465 & 0.055 & 0.507 \\
\cline { 2 - 5 } & 10 & 0.868 & 0.023 & 0.596 \\
\cline { 2 - 5 } & 15 & 0.964 & 0.052 & 0.614 \\
\cline { 2 - 5 } Epoxy/P-HNT & 20 & 0.886 & 0.040 & 0.593 \\
\cline { 2 - 5 } & 5 & 0.370 & 0.029 & 0.419 \\
\cline { 2 - 5 } & 10 & 0.363 & 0.025 & 0.426 \\
\hline \multirow{3}{*}{ Epoxy/A-HNT } & 15 & 0.347 & 0.039 & 0.415 \\
\cline { 2 - 5 } & 20 & 0.288 & 0.037 & 0.410 \\
\cline { 2 - 5 } & 5 & 0.482 & 0.138 & 0.528 \\
\hline & 10 & 0.837 & 0.179 & 0.616 \\
\cline { 2 - 5 } Epoxy/F-HNT & 15 & 0.823 & 0.161 & 0.614 \\
\cline { 2 - 5 } & 10 & 0.611 & 0.174 & 0.546 \\
\cline { 2 - 5 } & 15 & 0.380 & 0.070 & 0.409 \\
\hline & 20 & 0.318 & 0.052 & 0.400 \\
\hline
\end{tabular}




\subsubsection{Determining Degree of Reaction}

According to the Friedman and Malek methods the reaction model of neat epoxy and epoxy containing P-HNT, A-HNT and F-HNT correlated with Sestak and Berggren empirical kinetic model. By substituting Equation (9) in Equation (4) the curing reaction rate rewrite as follows:

$$
\frac{d \alpha}{d t}=\operatorname{Aexp}\left(-\frac{E_{\alpha}}{R T}\right) \alpha^{m}(1-\alpha)^{n},
$$

The kinetic parameters including the degrees of autocatalytic reaction $(n$ and $m$ ) and the frequency factor $(A)$ can be determined through the following equations:

$$
\begin{gathered}
\text { Value }=\ln \left(\frac{d \alpha}{d t}\right)+\frac{E_{\alpha}}{R T}-\ln \left[\frac{d(1-\alpha)}{d t}\right]-\frac{E_{\alpha}}{R T^{\prime}}=(n-m) \ln \left(\frac{1-\alpha}{\alpha}\right), \\
\text { ValueI }=\ln \left(\frac{d \alpha}{d t}\right)+\frac{E_{\alpha}}{R T}+\ln \left[\frac{d(1-\alpha)}{d t}\right]+\frac{E_{\alpha}}{R T^{\prime}}=(n+m) \ln \left(\alpha-\alpha^{2}\right)+2 \ln A
\end{gathered}
$$

By plloting ValueI vs. $\ln [(1-\alpha) / \alpha]$ a straight line is obtained which slope gives the value of $n-m$ (Figure 10). In addition, the value of $n+m$ and $2 \ln A$ can be obtained from the slope and intercept of the plot of ValueII vs. $\ln \left(\alpha-\alpha^{2}\right)$ (Figure 11).

(a)

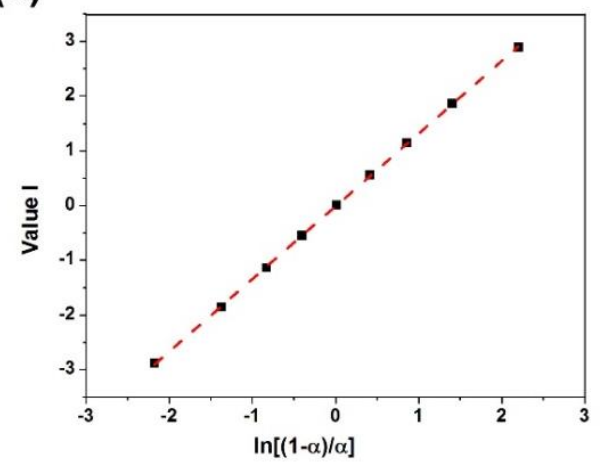

(c)

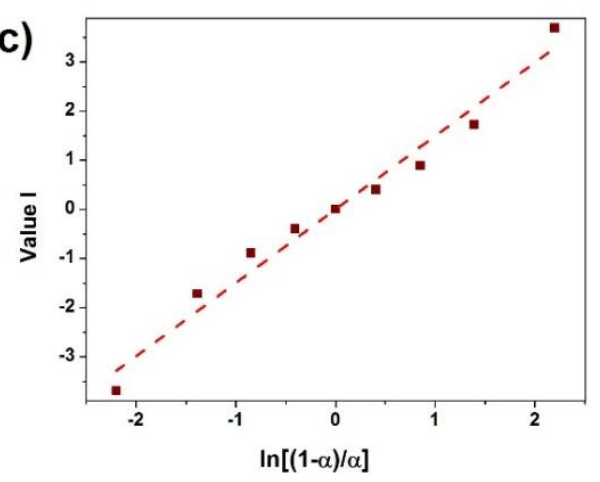

(b)

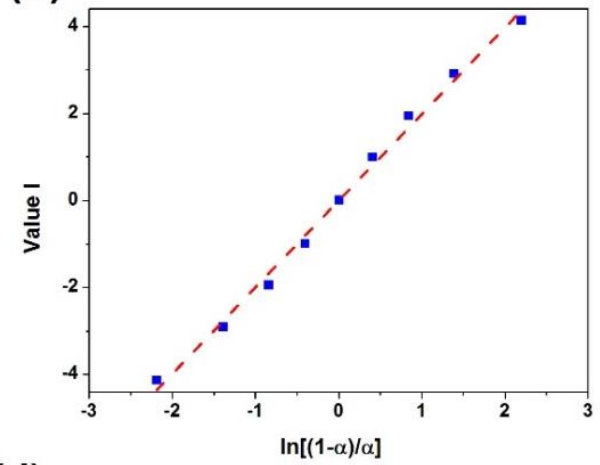

(d)

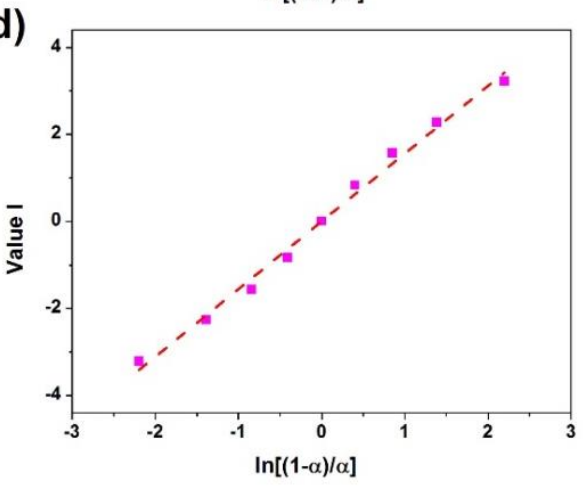

Figure 10. Plots of ValueI calculated using DSC data for (a) neat epoxy, (b) epoxy/P-HNT, (c) epoxy/A-HNT and (d) epoxy/F-HNT. 

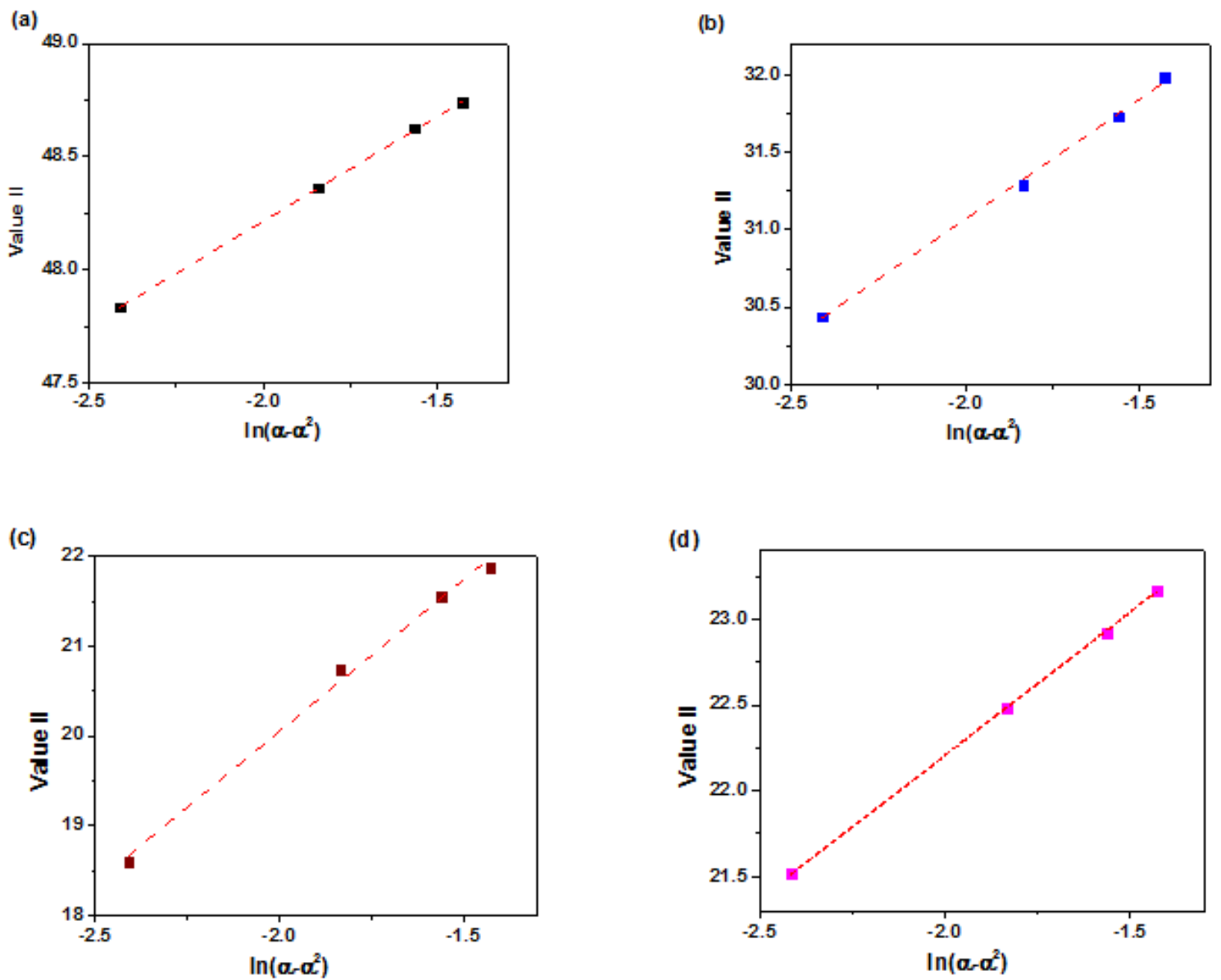

Figure 11. Plots of ValueII calculated using DSC data for (a) neat epoxy, (b) epoxy/P-HNT, (c) epoxy/A-HNT and (d) epoxy/F-HNT.

For calculating the values of $m, n$ and $\ln A$ from equations of 15 and 16 the $E_{\alpha}$ value was used as the average amount in different conversion based on Friedman and KAS methods and reported in Table 2.

As can be observed from Table 2, the trend of variation of kinetic parameters $(n, m$ and $\ln A)$ of epoxy system by addition of P-HNT, A-HNT and F-HNT obtained from Friedman and KAS methods are in well agreement with each other. For neat epoxy and its nanocomposites in all heating rates the overall reaction order $(m+n)$ is higher than unity which is indicative of complexity of the curing mechanism [49]. The results of kinetic parameters indicated an increase in autocatalytic reaction order $(m)$ by introduction of P-HNT into epoxy matrix. The reaction of hydroxyl groups of P-HNT with epoxy resin push the balance to the benefit of $-\mathrm{OH}$ groups on the surface of P-HNT towards epoxide ring opening via etherification autocatalytic reaction [50,51]. In the case of epoxy/A-HNT nanocomposite autocatalytic reaction order is lower in comparison with P-HNT due to the fact that A-HNT has lower hydroxyl groups compared to P-HNT. Because by alkali activation of HNT results inner hydroxyl groups removes as $\mathrm{Al}(\mathrm{OH})_{3}$ sheets which decreased the reaction between $\mathrm{OH}$ groups and epoxy rings. Moreover, addition of P-HNT, A-HNT and F-HNT decreased collisions between the curing moieties, as reflected in a drop in pre-exponential factor. Moreover, the lower amount of activation energy in the presence of F-HNT also reflects in the lower pre-exponential factor as can be observed in Table 2 . This reduction in the frequency factor, which is originated from the number of collisions between curing moieties, is attributed to the reduction of the segmental diffusion rates. 
Table 2. The kinetic parameters evaluated for the curing of pristine epoxy resin and its nanocomposites based on Friedman and KAS models at different heating rates.

\begin{tabular}{|c|c|c|c|c|c|c|c|c|}
\hline Designation & $\begin{array}{c}\text { Heating Rate } \\
\left({ }^{\circ} \mathrm{C} / \mathrm{min}\right)\end{array}$ & $\begin{array}{c}\bar{E}_{\alpha} \\
(\mathrm{kJ} / \mathrm{mol})\end{array}$ & $\ln (A)(1 / s)$ & Mean (1/s) & $m$ & Mean & $n$ & Mean \\
\hline \multicolumn{9}{|c|}{ Friedman } \\
\hline \multirow{4}{*}{ Epoxy } & 5 & \multirow{4}{*}{78.40} & 25.08 & \multirow{4}{*}{25.00} & 0.103 & \multirow{4}{*}{0.158} & 1.849 & \multirow{4}{*}{1.400} \\
\hline & 10 & & 25.18 & & 0.173 & & 1.309 & \\
\hline & 15 & & 24.94 & & 0.186 & & 1.133 & \\
\hline & 20 & & 24.79 & & 0.170 & & 1.307 & \\
\hline \multirow{4}{*}{ Epoxy/P-HNT } & 5 & \multirow{4}{*}{57.72} & 17.02 & \multirow{4}{*}{17.08} & 0.908 & \multirow{4}{*}{0.511} & 1.763 & \multirow{4}{*}{1.788} \\
\hline & 10 & & 17.02 & & 0.360 & & 1.741 & \\
\hline & 15 & & 17.14 & & 0.357 & & 1.800 & \\
\hline & 20 & & 17.14 & & 0.419 & & 1.849 & \\
\hline \multirow{4}{*}{ Epoxy/A-HNT } & 5 & \multirow{4}{*}{39.17} & 13.40 & \multirow{4}{*}{12.74} & 0.240 & \multirow{4}{*}{0.213} & 2.407 & \multirow{4}{*}{1.401} \\
\hline & 10 & & 12.49 & & 0.246 & & 0.943 & \\
\hline & 15 & & 12.56 & & 0.186 & & 0.978 & \\
\hline & 20 & & 12.49 & & 0.181 & & 1.277 & \\
\hline \multirow{4}{*}{ Epoxy/F-HNT } & 5 & \multirow{4}{*}{43.69} & 12.76 & \multirow{4}{*}{12.69} & 0.072 & \multirow{4}{*}{0.056} & 1.620 & \multirow{4}{*}{1.626} \\
\hline & 10 & & 12.78 & & 0.031 & & 1.683 & \\
\hline & 15 & & 12.63 & & 0.045 & & 1.623 & \\
\hline & 20 & & 12.59 & & 0.077 & & 1.578 & \\
\hline \multirow{5}{*}{ Epoxy } & & & KAS & & & & & \\
\hline & 5 & \multirow{4}{*}{71.15} & 22.66 & \multirow{4}{*}{22.66} & 0.013 & \multirow{4}{*}{0.060} & 1.767 & \multirow{4}{*}{1.343} \\
\hline & 10 & & 22.82 & & 0.070 & & 1.260 & \\
\hline & 15 & & 22.63 & & 0.086 & & 1.090 & \\
\hline & 20 & & 22.51 & & 0.070 & & 1.257 & \\
\hline \multirow{4}{*}{ Epoxy/P-HNT } & 5 & & 16.62 & & 0.911 & & 1.743 & \\
\hline & 10 & & 16.64 & & 0.365 & & 1.721 & \\
\hline & 15 & 50.50 & 16.76 & 10.70 & 0.362 & 0.515 & 1.780 & 1.768 \\
\hline & 20 & & 16.77 & & 0.423 & & 1.828 & \\
\hline & 5 & & 13.29 & & 0.220 & & 2.401 & \\
\hline FnoYv/A_HNT & 10 & & 12.39 & & 0.227 & & 0.941 & \\
\hline Eроху/A-HN 1 & 15 & 38.84 & 12.45 & 12.63 & 0.169 & 0.195 & 0.976 & 1.398 \\
\hline & 20 & & 12.38 & & 0.164 & & 1.274 & \\
\hline & 5 & & 13.61 & & 0.036 & & 1.664 & \\
\hline Enoyu/E_HNT & 10 & & 13.60 & & 0.007 & & 1.729 & \\
\hline Броху/г-nivi & 15 & 46.27 & 13.42 & 13.50 & 0.085 & 0.062 & 1.668 & 1.671 \\
\hline & 20 & & 13.37 & & 0.118 & & 1.623 & \\
\hline
\end{tabular}

\subsubsection{Model Validation}

By estimating activation energy and kinetic parameters, the value of curing rate of epoxy systems can be calculated from Equation (14) and compared with experimental data. Figures 12 and 13 represent the calculated curing rate for neat epoxy and its nanocomposites based on Friedman and KAS models, respectively, in comparison with the experimental data. As apparent, both Friedman and $K A S$ approaches match well with each other. In the case of neat epoxy both methods coincide with experimental curve. By contrast, some differences can be seen between experimental and predicted curing for epoxy system in the presence of P-HNT, A-HNT and F-HNT. By introduction of nanotubes the mobility of curing moieties decreased which results in some deviation between the predicted values and the experimental data. 
(a)
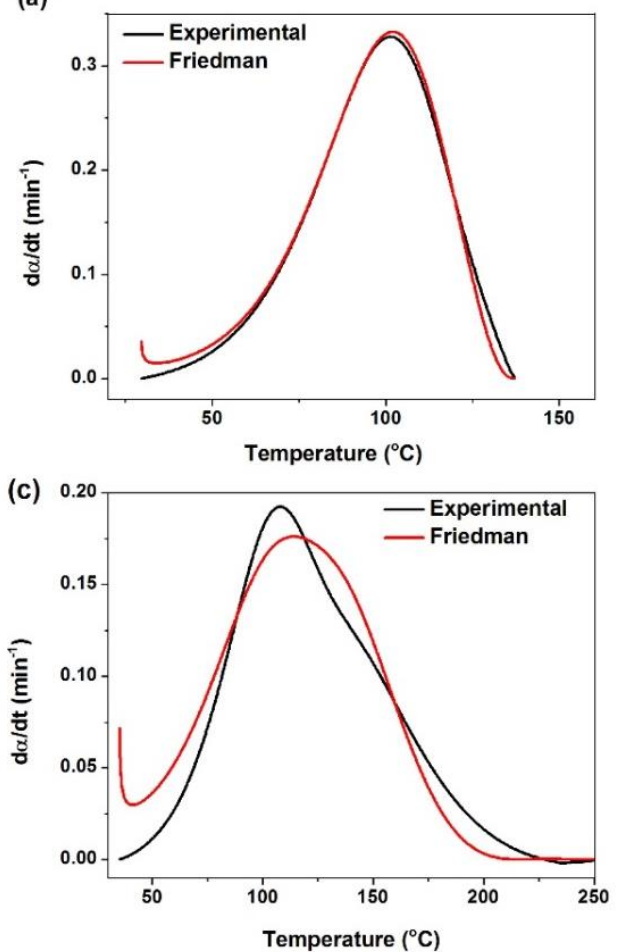
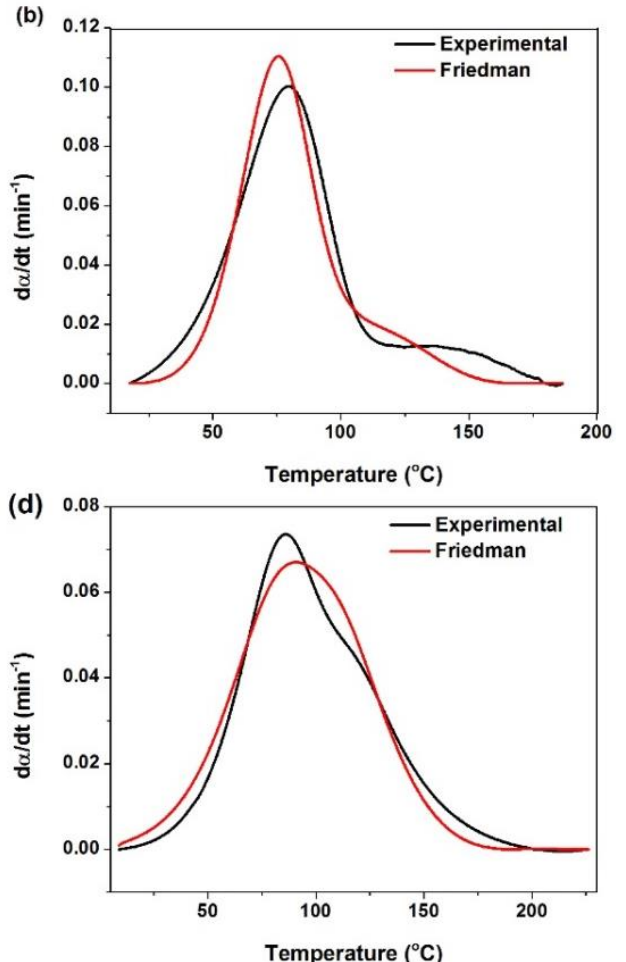

Figure 12. Comparison of experimental data with the kinetic models for (a) neat epoxy, (b) epoxy/P-HNT, (c) epoxy/ A-HNT and (d) epoxy/ F-HNT based on Friedman model.

(a)

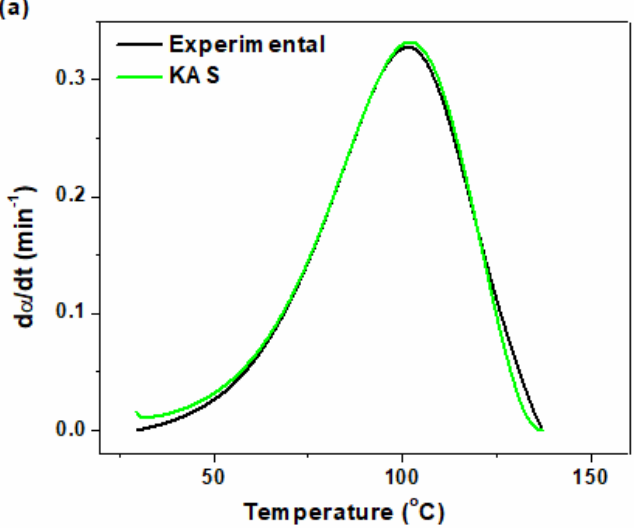

(c)

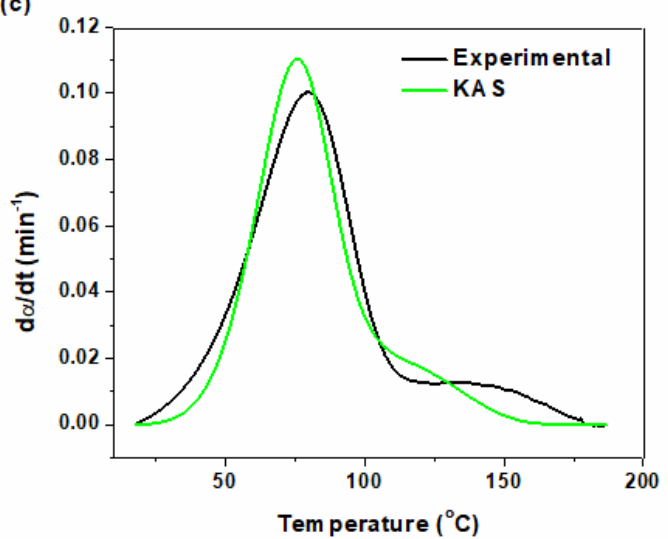

(b)

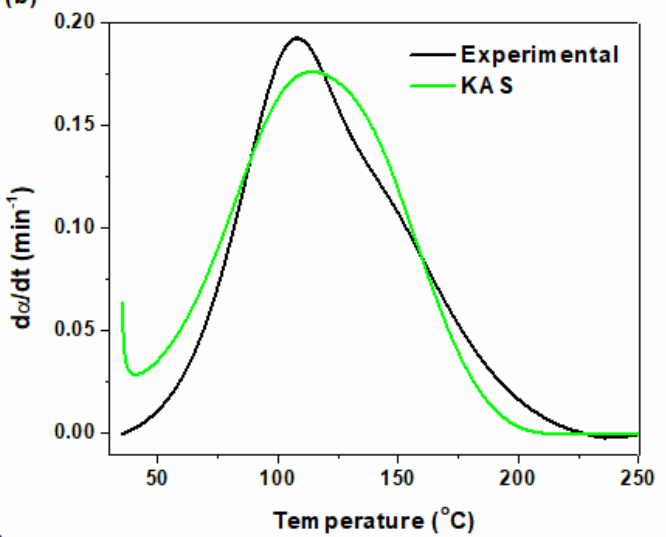

(d)

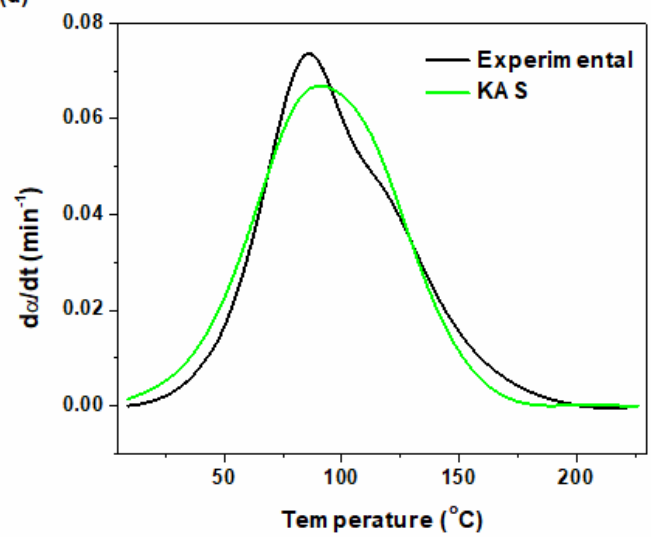

Figure 13. Comparison of experimental data with the kinetic models for (a) neat epoxy, (b) epoxy/P-HNT, (c) epoxy/ A-HNT and (d) epoxy/ F-HNT based on KAS model. 


\section{Conclusions}

Nonisothermal DSC was applied to study the cure kinetics of of epoxy/amine systems containing $0.2 \mathrm{wt} . \%$ P-HNT, A-HNT and F-HNT. The evolution of activation energy of neat epoxy as a function of curing conversion indicated an increasing trend due to viscosity rise which hindered the mobility of curing moieties. KAS model showed that average value of activation energy decreased from $71 \mathrm{~kJ} / \mathrm{mol}$ for neat epoxy to about 56, 39 and $46 \mathrm{~kJ} / \mathrm{mol}$ for epoxy nanocomposites containing P-HNT, A-HNT and F-HNT, respectively. The higher decline in activation energy of epoxy containing F-HNT compared to P-HNT incorporated epoxy system is due to epoxide groups on the surface of HNT which may results in better dispersion state and catalyzing the curing reactions between epoxy resin and curing agent by etherification reaction. By contrast, it was observed that the activation energy of the curing reaction calculated by Friedman and KAS methods decreased in the presence of A-HNT due to the decrease of $\mathrm{OH}$ groups caused by the removal of $\mathrm{Al}(\mathrm{OH})_{3}$ sheets from inner surface of HNT. Detailed analysis of cure in terms of kinetics parameters can be performed by monitoring the autocatalytic reaction degree. At low heating rate of $5{ }^{\circ} \mathrm{C} \mathrm{min}^{-1} \mathrm{~s}$, the value of $m$ increased from 0.107 for neat epoxy/amine system to the values of 0.908 and 0.24 for the epoxy/P-HNT and epoxy/A-HNT nanocomposites, respectively, whereas epoxy/F-HNT system had $m$ value of 0.072 as a sign of dominance of the non-catalytic reactions. This obviously denotes the catalytic effect of A-HNT, and more remarkably P-HNT. At high heating rate of $5{ }^{\circ} \mathrm{C} \mathrm{min}^{-1} \mathrm{~s}$, a similar behavior was observed. It can be concluded that introduction of HNT suppresses the mobility of curing moieties. As a result, deviation of experimental cure rate values from the predicted values obtained by KAS and Friedman methods was slightly observed.

Author Contributions: Conceptualization, M.R.S.; methodology, M.J.; software, S.M.R.P.; validation, M.J. \& Z.A.; formal analysis, V.A. \& H.A.; investigation, V.A. \& M.J.; data curation, M.J. and S.M.R.P.; writing-original draft preparation, V.A.; writing—review and editing, M.J., A.E., A.M. \& S.H.; visualization, H.V., K.F. \& M.R.G.; supervision, M.R.S.; All authors have read and agreed to the published version of the manuscript.

Funding: This research received no external funding.

Acknowledgments: The authors would like to acknowledge the Center of Excellence in Electrochemistry, School of Chemistry, College of Science, University of Tehran for providing the authors with laboratory equipment.

Conflicts of Interest: The authors declare no conflict of interest.

\section{References}

1. Jouyandeh, M.; Ali, J.A.; Akbari, V.; Aghazadeh, M.; Paran, S.M.R.; Naderi, G.; Saeb, M.R.; Ranjbar, Z.; Ganjali, M.R. Curing epoxy with polyvinylpyrrolidone (PVP) surface-functionalized MnxFe3-xO4 magnetic nanoparticles. Prog. Org. Coat. 2019, 136, 105247. [CrossRef]

2. Jouyandeh, M.; Ganjali, M.R.; Ali, J.A.; Aghazadeh, M.; Stadler, F.J.; Saeb, M.R. Curing epoxy with electrochemically synthesized MnxFe3-xO4 magnetic nanoparticles. Prog. Org. Coat. 2019, 136, 105199. [CrossRef]

3. Jouyandeh, M.; Ganjali, M.R.; Ali, J.A.; Akbari, V.; Karami, Z.; Aghazadeh, M.; Zarrintaj, P.; Saeb, M.R. Curing epoxy with polyethylene glycol (PEG) surface-functionalized GdxFe3-xO4 magnetic nanoparticles. Prog. Org. Coat. 2019, 137, 105283. [CrossRef]

4. Aliakbari, M.; Jazani, O.M.; Sohrabian, M.; Jouyandeh, M.; Saeb, M.R. Multi-nationality epoxy adhesives on trial for future nanocomposite developments. Prog. Org. Coat. 2019, 133, 376-386. [CrossRef]

5. Jouyandeh, M.; Rahmati, N.; Movahedifar, E.; Hadavand, B.S.; Karami, Z.; Ghaffari, M.; Taheri, P.; Bakhshandeh, E.; Vahabi, H.; Ganjali, M.R.; et al. Properties of nano-Fe3O4 incorporated epoxy coatings from Cure Index perspective. Prog. Org. Coat. 2019, 133, 220-228. [CrossRef]

6. Bayat, S.; Moini Jazani, O.; Molla-Abbasi, P.; Jouyandeh, M.; Saeb, M.R. Thin films of epoxy adhesives containing recycled polymers and graphene oxide nanoflakes for metal/polymer composite interface. Prog. Org. Coat. 2019, 136, 105201. [CrossRef]

7. He, X.; Zhang, D.; Li, H.; Fang, J.; Shi, L. Shape and size effects of ceria nanoparticles on the impact strength of ceria/epoxy resin composites. Particuology 2011, 9, 80-85. [CrossRef] 
8. Tikhani, F.; Jouyandeh, M.; Jafari, S.H.; Chabokrow, S.; Ghahari, M.; Gharanjig, K.; Klein, F.; Hampp, N.; Ganjali, M.R.; Formela, K.; et al. Cure Index demonstrates curing of epoxy composites containing silica nanoparticles of variable morphology and porosity. Prog. Org. Coat. 2019, 135, 176-184. [CrossRef]

9. Jouyandeh, M.; Ganjali, M.R.; Hadavand, B.S.; Aghazadeh, M.; Akbari, V.; Shammiry, F.; Saeb, M.R. Curing epoxy with polyvinyl chloride (PVC) surface-functionalized CoxFe3-xO4 nanoparticles. Prog. Org. Coat. 2019, 137, 105364. [CrossRef]

10. Jouyandeh, M.; Ganjali, M.R.; Ali, J.A.; Aghazadeh, M.; Stadler, F.J.; Saeb, M.R. Curing epoxy with electrochemically synthesized CoxFe3-xO4 magnetic nanoparticles. Prog. Org. Coat. 2019, 137, 105252. [CrossRef]

11. Jouyandeh, M.; Ganjali, M.R.; Ali, J.A.; Aghazadeh, M.; Karimzadeh, I.; Formela, K.; Colom, X.; Cañavate, J.; Saeb, M.R. Curing epoxy with ethylenediaminetetraacetic acid (EDTA) surface-functionalized CoxFe3-xO4 magnetic nanoparticles. Prog. Org. Coat. 2019, 136, 105248. [CrossRef]

12. Karami, Z.; Jouyandeh, M.; Ali, J.A.; Ganjali, M.R.; Aghazadeh, M.; Maadani, M.; Rallini, M.; Luzi, F.; Torre, L.; Puglia, D.; et al. Cure Index for labeling curing potential of epoxy/LDH nanocomposites: A case study on nitrate anion intercalated Ni-Al-LDH. Prog. Org. Coat. 2019, 136, 105228. [CrossRef]

13. Jouyandeh, M.; Tikhani, F.; Shabanian, M.; Movahedi, F.; Moghari, S.; Akbari, V.; Gabrion, X.; Laheurte, P.; Vahabi, H.; Saeb, M.R. Synthesis, characterization, and high potential of 3D metal-organic framework (MOF) nanoparticles for curing with epoxy. J. Alloy. Compd. 2020, 829, 154547. [CrossRef]

14. Yuan, P.; Tan, D.; Annabi-Bergaya, F. Properties and applications of halloysite nanotubes: Recent research advances and future prospects. Appl. Clay Sci. 2015, 112-113, 75-93. [CrossRef]

15. Joshi, A.; Abdullayev, E.; Vasiliev, A.; Volkova, O.; Lvov, Y.J.L. Interfacial modification of clay nanotubes for the sustained release of corrosion inhibitors. Langmuir 2013, 29, 7439-7448. [CrossRef] [PubMed]

16. Lvov, Y.; Wang, W.; Zhang, L.; Fakhrullin, R.J.A.M. Halloysite clay nanotubes for loading and sustained release of functional compounds. Adv. Mater. 2016, 28, 1227-1250. [CrossRef]

17. Liu, M.; Jia, Z.; Jia, D.; Zhou, C. Recent advance in research on halloysite nanotubes-polymer nanocomposite. Prog. Polym. Sci. 2014, 39, 1498-1525. [CrossRef]

18. Liu, M.; Guo, B.; Du, M.; Cai, X.; Jia, D.J.N. Properties of halloysite nanotube-epoxy resin hybrids and the interfacial reactions in the systems. Nanotechnology 2007, 18, 455703. [CrossRef]

19. Li, C.; Liu, J.; Qu, X.; Yang, Z. A general synthesis approach toward halloysite-based composite nanotube. J. Appl. Polym. Sci. 2009, 112, 2647-2655. [CrossRef]

20. Vahabi, H.; Saeb, M.R.; Formela, K.; Cuesta, J.-M.L. Flame retardant epoxy/halloysite nanotubes nanocomposite coatings: Exploring low-concentration threshold for flammability compared to expandable graphite as superior fire retardant. Prog. Org. Coat. 2018, 119, 8-14. [CrossRef]

21. Vahabi, H.; Jouyandeh, M.; Cochez, M.; Khalili, R.; Vagner, C.; Ferriol, M.; Movahedifar, E.; Ramezanzadeh, B.; Rostami, M.; Ranjbar, Z.; et al. Short-lasting fire in partially and completely cured epoxy coatings containing expandable graphite and halloysite nanotube additives. Prog. Org. Coat. 2018, 123, 160-167. [CrossRef]

22. Vahabi, H.; Sonnier, R.; Taguet, A.; Otazaghine, B.; Saeb, M.R.; Beyer, G. 3-Halloysite nanotubes (HNTs)/polymer nanocomposites: Thermal degradation and flame retardancy. In Clay Nanoparticles; Cavallaro, G., Fakhrullin, R., Pasbakhsh, P., Eds.; Elsevier: Amsterdam, The Netherlands, 2020.

23. Kamble, R.; Ghag, M.; Gaikawad, S.; Panda, B.K. Halloysite Nanotubes and Applications: A Review. J. Adv. Sci. Res. 2012, 3, 25-29.

24. Du, M.; Guo, B.; Jia, D. Newly emerging applications of halloysite nanotubes: A review. Polym. Int. 2010, 59, 574-582. [CrossRef]

25. Vahedi, V.; Pasbakhsh, P.; Chai, S.-P. Toward high performance epoxy/halloysite nanocomposites: New insights based on rheological, curing, and impact properties. Mater. Des. 2015, 68, 42-53. [CrossRef]

26. Jouyandeh, M.; Karami, Z.; Moini Jazani, O.; Formela, K.; Paran, S.M.R.; Jannesari, A.; Saeb, M.R. Curing epoxy resin with anhydride in the presence of halloysite nanotubes: The contradictory effects of filler concentration. Prog. Org. Coat. 2019, 126, 129-135. [CrossRef]

27. Akbari, V.; Najafi, F.; Vahabi, H.; Jouyandeh, M.; Badawi, M.; Morisset, S.; Ganjali, M.R.; Saeb, M.R. Surface chemistry of halloysite nanotubes controls the curability of low filled epoxy nanocomposites. Prog. Org. Coat. 2019, 135, 555-564. [CrossRef]

28. Jouyandeh, M.; Paran, S.M.R.; Jannesari, A.; Saeb, M.R. 'Cure Index' for thermoset composites. Prog. Org. Coat. 2019, 127, 429-434. [CrossRef] 
29. Jouyandeh, M.; Paran, S.M.R.; Jannesari, A.; Puglia, D.; Saeb, M.R. Protocol for nonisothermal cure analysis of thermoset composites. Prog. Org. Coat. 2019, 131, 333-339. [CrossRef]

30. Jouyandeh, M.; Zarrintaj, P.; Ganjali, M.R.; Ali, J.A.; Karimzadeh, I.; Aghazadeh, M.; Ghaffari, M.; Saeb, M.R. Curing epoxy with electrochemically synthesized GdxFe3-xO4 magnetic nanoparticles. Prog. Org. Coat. 2019, 136, 105245. [CrossRef]

31. Jouyandeh, M.; Ganjali, M.R.; Ali, J.A.; Aghazadeh, M.; Stadler, F.J.; Saeb, M.R. Curing epoxy with electrochemically synthesized NixFe3-xO4 magnetic nanoparticles. Prog. Org. Coat. 2019, 136, 105198. [CrossRef]

32. Tikhani, F.; Moghari, S.; Jouyandeh, M.; Laoutid, F.; Vahabi, H.; Saeb, M.R.; Dubois, P. Curing Kinetics and Thermal Stability of Epoxy Composites Containing Newly Obtained Nano-Scale Aluminum Hypophosphite (AlPO2). Polymers 2020, 12, 644. [CrossRef] [PubMed]

33. Karami, Z.; Jouyandeh, M.; Ali, J.A.; Ganjali, M.R.; Aghazadeh, M.; Paran, S.M.R.; Naderi, G.; Puglia, D.; Saeb, M.R. Epoxy/layered double hydroxide (LDH) nanocomposites: Synthesis, characterization, and Excellent cure feature of nitrate anion intercalated Zn-Al LDH. Prog. Org. Coat. 2019, 136, 105218. [CrossRef]

34. Jouyandeh, M.; Ali, J.A.; Aghazadeh, M.; Formela, K.; Saeb, M.R.; Ranjbar, Z.; Ganjali, M.R. Curing epoxy with electrochemically synthesized ZnxFe3-xO4 magnetic nanoparticles. Prog. Org. Coat. 2019, 136, 105246. [CrossRef]

35. Ghiyasi, S.; Sari, M.G.; Shabanian, M.; Hajibeygi, M.; Zarrintaj, P.; Rallini, M.; Torre, L.; Puglia, D.; Vahabi, H.; Jouyandeh, M.; et al. Hyperbranched poly(ethyleneimine) physically attached to silica nanoparticles to facilitate curing of epoxy nanocomposite coatings. Prog. Org. Coat. 2018, 120, 100-109. [CrossRef]

36. Jouyandeh, M.; Shabanian, M.; Khaleghi, M.; Paran, S.M.R.; Ghiyasi, S.; Vahabi, H.; Formela, K.; Puglia, D.; Saeb, M.R. Acid-aided epoxy-amine curing reaction as reflected in epoxy/Fe3O4 nanocomposites: Chemistry, mechanism, and fracture behavior. Prog. Org. Coat. 2018, 125, 384-392. [CrossRef]

37. Jouyandeh, M.; Jazani, O.M.; Navarchian, A.H.; Shabanian, M.; Vahabi, H.; Saeb, M.R. Surface engineering of nanoparticles with macromolecules for epoxy curing: Development of super-reactive nitrogen-rich nanosilica through surface chemistry manipulation. Appl. Surf. Sci. 2018, 447, 152-164. [CrossRef]

38. Paran, S.M.R.; Vahabi, H.; Jouyandeh, M.; Ducos, F.; Formela, K.; Saeb, M.R. Thermal decomposition kinetics of dynamically vulcanized polyamide 6-acrylonitrile butadiene rubber-halloysite nanotube nanocomposites. J. Appl. Polym. Sci. 2019, 136, 47483. [CrossRef]

39. Vyazovkin, S.; Burnham, A.K.; Criado, J.M.; Pérez-Maqueda, L.A.; Popescu, C.; Sbirrazzuoli, N. ICTAC Kinetics Committee recommendations for performing kinetic computations on thermal analysis data. Thermochim. Acta 2011, 520, 1-19. [CrossRef]

40. Friedman, H.L. New methods for evaluating kinetic parameters from thermal analysis data. J. Polym. Sci. Part C Polym. Lett. 1969, 7, 41-46. [CrossRef]

41. Kissinger, H.E. Reaction kinetics in differential thermal analysis. Anal. Chem. 1957, 29, 1702-1706. [CrossRef]

42. Jouyandeh, M.; Ganjali, M.R.; Ali, J.A.; Aghazadeh, M.; Paran, S.M.R.; Naderi, G.; Saeb, M.R.; Thomas, S. Curing epoxy with polyvinylpyrrolidone (PVP) surface-functionalized ZnxFe3-xO4 magnetic nanoparticles. Prog. Org. Coat. 2019, 136, 105227. [CrossRef]

43. Jouyandeh, M.; Karami, Z.; Ali, J.A.; Karimzadeh, I.; Aghazadeh, M.; Laoutid, F.; Vahabi, H.; Saeb, M.R.; Ganjali, M.R.; Dubois, P. Curing epoxy with polyethylene glycol (PEG) surface-functionalized NixFe3-xO4magnetic nanoparticles. Prog. Org. Coat. 2019, 136, 105250. [CrossRef]

44. Jouyandeh, M.; Moini Jazani, O.; Navarchian, A.; Saeb, M. Epoxy coatings physically cured with hydroxyl-contained silica nanospheres and halloysite nanotubes. Prog. Color Color. Coat. 2018, 11, 199-207.

45. Jouyandeh, M.; Paran, S.M.R.; Khadem, S.S.M.; Ganjali, M.R.; Akbari, V.; Vahabi, H.; Saeb, M.R. Nonisothermal cure kinetics of epoxy/MnxFe3-xO4 nanocomposites. Prog. Org. Coat. 2020, 140, 105505. [CrossRef]

46. Jouyandeh, M.; Paran, S.M.R.; Shabanian, M.; Ghiyasi, S.; Vahabi, H.; Badawi, M.; Formela, K.; Puglia, D.; Saeb, M.R. Curing behavior of epoxy/Fe3O4 nanocomposites: A comparison between the effects of bare $\mathrm{Fe} 3 \mathrm{O} 4, \mathrm{Fe} 3 \mathrm{O} 4 / \mathrm{SiO} 2 /$ chitosan and $\mathrm{Fe} 3 \mathrm{O} 4 / \mathrm{SiO} 2 /$ chitosan/imide/phenylalanine-modified nanofillers. Prog. Org. Coat. 2018, 123, 10-19. [CrossRef]

47. Šesták, J.; Berggren, G. Study of the kinetics of the mechanism of solid-state reactions at increasing temperatures. Thermochim. Acta 1971, 3, 1-12. [CrossRef] 
48. Saeb, M.R.; Rastin, H.; Nonahal, M.; Ghaffari, M.; Jannesari, A.; Formela, K. Cure kinetics of epoxy/MWCNTs nanocomposites: Nonisothermal calorimetric and rheokinetic techniques. J. Appl. Polym. Sci. 2017, 134, 45221. [CrossRef]

49. Saeb, M.R.; Nonahal, M.; Rastin, H.; Shabanian, M.; Ghaffari, M.; Bahlakeh, G.; Ghiyasi, S.; Khonakdar, H.A.; Goodarzi, V.; Vijayan, P.P.; et al. Calorimetric analysis and molecular dynamics simulation of cure kinetics of epoxy/chitosan-modified Fe3O4 nanocomposites. Prog. Org. Coat. 2017, 112, 176-186. [CrossRef]

50. Saeb, M.; Vahabi, H.; Jouyandeh, M.; Movahedifar, E.; Khalili, R. Epoxy-based flame retardant nanocomposite coatings: Comparison between functions of expandable graphite and halloysite nanotubes. Prog. Color Color. Coat. 2017, 10, 245-252.

51. Jouyandeh, M.; Jazani, O.M.; Navarchian, A.H.; Shabanian, M.; Vahabi, H.; Saeb, M.R. Bushy-surface hybrid nanoparticles for developing epoxy superadhesives. Appl. Surf. Sci. 2019, 479, 1148-1160. [CrossRef]

(C) 2020 by the authors. Licensee MDPI, Basel, Switzerland. This article is an open access article distributed under the terms and conditions of the Creative Commons Attribution (CC BY) license (http://creativecommons.org/licenses/by/4.0/). 